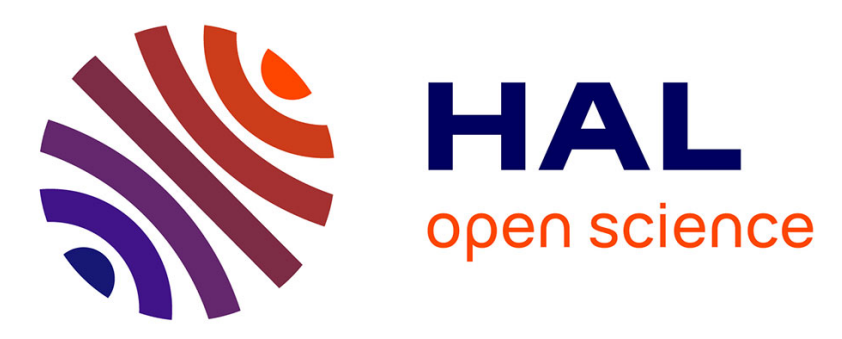

\title{
Indian Ocean and Indian summer monsoon: relationships without ENSO in ocean-atmosphere coupled simulations
}

Julien Crétat, Pascal Terray, Sébastien Masson, K. P. Sooraj, Mathew Koll Roxy

\section{To cite this version:}

Julien Crétat, Pascal Terray, Sébastien Masson, K. P. Sooraj, Mathew Koll Roxy. Indian Ocean and Indian summer monsoon: relationships without ENSO in ocean-atmosphere coupled simulations. Climate Dynamics, 2017, 49 (4), pp.1429-1448. 10.1007/s00382-016-3387-x . hal-01393495

\section{HAL Id: hal-01393495 https://hal.sorbonne-universite.fr/hal-01393495}

Submitted on 7 Nov 2016

HAL is a multi-disciplinary open access archive for the deposit and dissemination of scientific research documents, whether they are published or not. The documents may come from teaching and research institutions in France or abroad, or from public or private research centers.
L'archive ouverte pluridisciplinaire HAL, est destinée au dépôt et à la diffusion de documents scientifiques de niveau recherche, publiés ou non, émanant des établissements d'enseignement et de recherche français ou étrangers, des laboratoires publics ou privés. 
$37 *$ Corresponding author address: Julien Crétat

38 julien.cretat@locean-ipsl.upmc.fr
Indian Ocean and Indian summer monsoon: relationships without ENSO in ocean-atmosphere coupled simulations

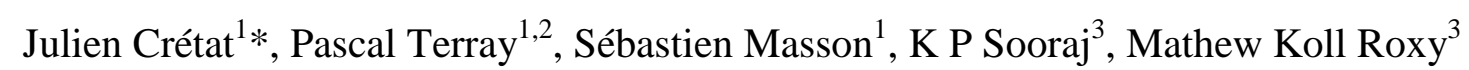

${ }^{1}$ Sorbonne Universités (UPMC, Univ Paris 06)-CNRS-IRD-MNHN, LOCEAN Laboratory, IPSL, Paris, France

${ }^{2}$ Indo-French Cell for Water Sciences, IISC-NIO-IITM-IRD Joint International Laboratory, IITM, Pune, India

${ }^{3}$ Centre for Climate Change Research, Indian Institute of Tropical Meteorology, Pune, India Submitted to Climate Dynamics

$05 / 19 / 2016$

$$
\text { Revised }
$$

$08 / 24 / 2016$

\section{Accepted}

$10 / 07 / 2016$ 
The relationship between the Indian Ocean and the Indian Summer Monsoon (ISM) and their respective influence over the Indo-Western North Pacific (WNP) region are examined in the absence of El Niño Southern Oscillation (ENSO) in two partially decoupled global experiments. ENSO is removed by nudging the tropical Pacific simulated Sea Surface Temperature (SST) toward SST climatology from either observations or a fully coupled control run. The control reasonably captures the observed relationships between ENSO, ISM and the Indian Ocean Dipole (IOD).

Despite weaker amplitude, IODs do exist in the absence of ENSO and are triggered by a boreal spring ocean-atmosphere coupled mode over the South-East Indian Ocean similar to that found in the presence of ENSO. These pure IODs significantly affect the tropical Indian

Ocean throughout boreal summer, inducing a significant modulation of both the local Walker and Hadley cells. This meridional circulation is masked in the presence of ENSO. However, these pure IODs do not significantly influence the Indian subcontinent rainfall despite overestimated SST variability in the eastern equatorial Indian Ocean compared to observations. On the other hand, they promote a late summer cross-equatorial quadrupole rainfall pattern linking the tropical Indian Ocean with the WNP, inducing important zonal shifts of the Walker circulation despite the absence of ENSO.

Surprisingly, the interannual ISM rainfall variability is barely modified and the Indian Ocean does not force the monsoon circulation when ENSO is removed. On the contrary, the monsoon circulation significantly forces the Arabian Sea and Bay of Bengal SSTs, while its connection with the western tropical Indian Ocean is clearly driven by ENSO in our 
64 numerical framework. Convection and diabatic heating associated with above-normal ISM

65 induce a strong response over the WNP, even in the absence of ENSO, favoring moisture 66 convergence over India.

67

68

69 Keywords: Coupled climate model - El Niño-Southern Oscillation - Indian Ocean (Dipole)

70 - Indian summer monsoon - Ocean-atmosphere interactions - Rainfall 


\section{1) Introduction}

72

The Indian Summer Monsoon (ISM) provides about $75-90 \%$ of annual rainfall over India

74 from June to September (JJAS) with significant year-to-year variability. Predicting its interannual variations is of utmost importance as ISM is critical for the economy and agriculture of the country, with more than a billion people depending on fresh-water and farming.

The interannual variability of ISM Rainfall (ISMR) tightly relates to the El Niño Southern Oscillation (ENSO) phenomenon (e.g., Walker 1924; Sikka 1980; Rasmusson and Carpenter 1983). The Walker circulation shifts eastward in the Indian sector during El Niños, inducing anomalous subsidence and reduced rainfall over India, and vice versa during La Niñas (Wang et al. 2005). In addition to ENSO, many studies have pointed out significant connections between ISMR and the Indian Ocean (Rao and Goswami 1988; Ashok et al. 2001, 2004; Gadgil et al. 2004, 2005, 2007; Krishnan et al. 2003; Krishnan and Swapna 2009; Clark et al. 2000; Terray et al. 2003, 2007; Yang et al. 2007; Izumo et al. 2008; Park et al. 2010; Boschat et al. 2011; Roxy et al. 2015; Shukla and Huang 2016a).

In particular, the Indian Ocean Dipole (IOD, Reverdin et al. 1986; Saji et al. 1999; Webster et al. 1999; Murtugudde et al. 2000; Gadgil et al. 2004) has a two-way interaction with the ISM. Positive IOD events (pIODs) are associated with cooler (warmer) than normal SSTs in the eastern equatorial (western tropical) Indian Ocean, and reversely during negative IOD events (nIODs). The IOD is one of the main ocean-atmosphere coupled modes of variability in the Indian Ocean sector and its existence relates to coupled dynamics in the Indian Ocean (Annamalai et al. 2003; Fischer et al. 2005; Spencer et al. 2005; Behera et al. 2006). Its 
growth during boreal summer and peak in September-November (SON) are related to both wind-thermocline-SST and wind-evaporation-SST feedbacks over the equatorial Indian Ocean and off the coast of Sumatra (Li et al. 2003; Spencer et al. 2005). It is very often triggered by ENSO, leading to a hot debate whether IOD exists without ENSO or not (Yamagata et al. 2002; Gualdi et al. 2003; Wu and Kirtman 2004; Fischer et al. 2005; Behera et al. 2006; Roxy et al. 2010; Dommenget 2011; Krishnaswamy et al. 2015; Zhao and Nigam 2015; Wang et al. 2016), and can also be triggered by subsurface dynamics independently from ENSO (Rao et al. 2002).

\section{The IOD-ISM relationship does not necessarily reach the statistical significance level when} considering long-term observed time-series (Gadgil et al. 2004, 2005, 2007; Ihara et al. 2007). The way IODs can influence ISM remains also highly controversial. Some authors suggest a direct influence through moisture transport over the western Indian Ocean or modifications in the local Hadley cell, with enhanced ascendance (subsidence) and a northward (southward) shift of its uplift branch over India during pIODs (nIODs) that enhances (reduces) ISM (Ashok et al. 2001, 2004; Gadgil et al. 2004; Behera et al. 2005; Ashok and Saji 2007; Ummenhofer et al. 2011). Others suggest that IODs counteract the influence of ENSO on ISM and that the IOD-ISM relationship varies complementarily to the ENSO-ISM relationship at longer timescales. As an illustration, the IOD-ISM relationship has strengthened in the recent decades (Ashok et al. 2001, 2004; Ashok and Saji 2007; Izumo et al. 2010; Ummenhofer et al. 2011; Krishnaswamy et al. 2015) due to non-uniform warming of the Indian Ocean (Ihara et al. 2008; Cai et al. 2009; Roxy et al. 2014), while the reverse is observed for the ENSO-ISM relationship (Kumar et al. 1999; Ashrit et al. 2001; Ihara et al. 2008). However, El Niños (La Niñas) tend to be associated with pIODs (nIODs) by favoring easterly (westerly) wind anomalies over the eastern equatorial Indian Ocean during boreal spring, which trigger 
121 coupled dynamics over the equatorial Indian Ocean (Annamalai et al. 2003; Li et al. 2003;

122 Gualdi et al. 2003; Ashok et al. 2003; Bracco et al. 2005; Fischer et al. 2005; Behera et al. 123 2006). More recently, IODs have also been suggested as potential trigger of ENSO, with

124 nIODs at a particular year tending to be followed by El Niños in the subsequent year, and 125 pIODs by La Niñas (Luo et al. 2010; Izumo et al. 2010, 2014; Zhou et al. 2015; Jourdain et al. 126 2016).

The way around, ISMR has also been shown to influence Indian Ocean variability, including IOD variability. Many studies have suggested that tropical Indian Ocean SSTs may be considered as a passive element of the ISM system at the interannual timescale (Shukla 1987).

131 A strong ISM can favor either nIODs by producing westerly wind anomalies at the equator 132 (e.g., Loschnigg et al. 2003; Kulkarni et al. 2007; Webster and Hoyos 2010), or pIODs by 133 inducing southeasterly wind anomalies along the western coast of Sumatra (Annamalai et al. 134 2003; Krishnan and Swapna 2009). Note finally that the ENSO-IOD-ISM system could be 135 part of the Tropical Biennial Oscillation (TBO; Yasunari 1991; Meehl and Arblaster 2002; 136 Meehl et al. 2003; Loschnigg et al. 2003; Terray et al. 2005; Drbohlav et al. 2007; Webster 137 and Hoyos 2010).

139 This brief review indicates that there are still large uncertainties in the sign and amplitude of 140 the two-way IOD-ISM relationship, mainly because of the strong influence exerted by ENSO 141 on both IOD and ISM. A way to clarify this two-way relationship is to untangle ENSO142 induced and no-ENSO IOD-ISM relationships. The traditional way to do so consists in 143 compositing cases for which, e.g., IODs do not co-occur with ENSOs (Ashok et al. 2003; Saji 144 and Yamagata 2003; Pokhrel et al. 2012; Cherchi and Navarra 2013), or in linearly removing 145 the influence of ENSO (Clark et al. 2000; Guan et al. 2003; Pillai and Mohankumar 2010; 
146 Shukla and Huang 2016a). These two classical approaches remain, however, questionable

147 since the number of pure IODs is very small in the observation record and ENSO influence 148 can be delayed over time and is not linear (Compo and Sardeshmukh 2010). SST-forced 149 atmospheric simulations with imposed SST patterns have also been used to mimic the 150 influence of pIODs or nIODs on ISM (Ashok et al. 2001, 2004), but these models do not 151 account for the coupled nature of the ISM (Wu and Kirtman 2004; Wang et al. 2004, 2005). A

152 more physically consistent approach is using coupled ocean-atmosphere simulations with 153 partial decoupling over a region of interest. Such approach has been already successfully used 154 to analyze the roles of Indian and Atlantic Oceans on ENSO (Luo et al. 2010; Santoso et al. 155 2012; Terray et al. 2016), the impacts of SST errors on ISM (Prodhomme et al. 2014), and the 156 IOD evolution and its forcing mechanisms in the absence of ENSO (Fischer et al. 2005; 157 Behera et al. 2006; Wang et al. 2016).

159 Here, we build upon these previous successes and make use of a partial coupling strategy to 160 clarify the two-way synchronous IOD-ISM relationships in the absence of ENSO. Two 161 dedicated sensitivity experiments are run with a state-of-the-art Atmosphere-Ocean Global 162 Climate Model (AOGCM) with tropical Pacific SSTs nudged toward SST climatology 163 derived from a control run or observational data. These two experiments allow documenting 164 the ISM and IOD climatology and variability, and understanding the two-way interactions 165 between ISM and IOD and their remote influence without ENSO. The differences between 166 the two nudged experiments, if any, will be used to test the robustness of the results and the 167 impact of the mean SST state changes on these characteristics.

169 The paper is organized as follows. Section 2 presents the observations used for model 170 validation, the model experiments, and the methodology used for analyzing the two-way 
171 synchronous IOD-ISM relationships without ENSO. Section 3 is model validation and

172 discusses the basic effects of removing ENSO on both ISM and IOD. Section 4 analyzes the

173 influence of IOD and ISM in the presence and absence of ENSO over the Indo-Western

174 North Pacific sector, including the two-way synchronous IOD-ISM relationships. Section 5

175 gives main conclusions and discussion.

2) Experimental setup, observations and methodology

\section{1) Experimental setup}

Three global simulations are run using the SINTEX-F2 AOGCM (Masson et al. 2012) with the ECHAM5.3 atmosphere (Roeckner et al. 2003) at T106 spectral resolution $\left(\sim 1.125^{\circ} \mathrm{x}\right.$ $1.125^{\circ}$ ) and 31 hybrid sigma-pressure levels, and the NEMO ocean (Madec 2008) at $0.5^{\circ} \mathrm{x}$ $0.5^{\circ}$ horizontal resolution, 31 vertical levels and with the LIM2 ice model (Timmermann et al. 2005). The two model components are coupled using the Ocean-Atmosphere-Sea-Ice-Soil (OASIS3) coupler (Valcke 2006). The coupling information is exchanged every $2 \mathrm{~h}$ with no flux correction. The model does not require flux adjustment to maintain a near stable climate, and accurately simulates the tropical Pacific SST mean state, ENSO variability, and the monsoon-ENSO relationships (Masson et al. 2012; Terray et al. 2012, 2016).

192 The first simulation is a 210-yr fully coupled ocean-atmosphere experiment (Terray et al. 193 2016). It is used as a control (CTL hereafter) for ensuring that SINTEX-F2 simulates 194 reasonably both the mean tropical climate and the ENSO-IOD-ISM system and allows an 195 objective assessment of the effects of ENSO on the IOD and ISM statistics in Section 3. The 
two remaining simulations are 110- and 50-yr integrations (FTPC and FTPC-obs,

197 respectively) similar to CTL, except over the tropical Pacific (see domain defined by dark 198 blue shading in Fig. 1h,j) where SSTs are nudged toward the daily SST climatology from 199 CTL in FTPC and the 1982-2010 AVHRR-V2 daily Optimum Interpolation SST 200 observations (Reynolds et al. 2007) in FTPC-obs. Following Luo et al. (2005), the nudging 201 method used in these two simulations modifies the non-solar heat fluxes in the tropical Pacific 202 Ocean through a correction term, scaling with the SST model error, that completely removes 203 ENSO-scale variability (Prodhomme et al. 2015; Terray et al. 2016). The damping term in 204 this nudging technique $\left(-2400 \mathrm{~W} \mathrm{~m}^{-2} \mathrm{~K}^{-1}\right)$ corresponds to the 1-day relaxation time for 205 temperature in a 50-m ocean layer. The only difference between the two no-ENSO 206 experiments is the tropical Pacific SST bias correction in FTPC-obs since the nudging is done 207 toward the AVHRR-V2 SST climatology in this simulation. Thus, the comparison between 208 FTPC and FTPC-obs allows testing the robustness and sensitivity of our results to the mean 209 background SST in the tropical Pacific. Table 1 summarizes the coupling strategy utilized for 210 each simulation, and all the following analyses exclude the first 10 years to let the three 211 simulations spin-up.

\section{2) Observations and methodology}

215 The Hadley Centre Sea Ice and Sea Surface Temperature dataset (HadISST; Rayner et al. 216 2003) is used for evaluating the CTL ability in simulating the annual mean SST climatology 217 and its monthly variability. To foster direct comparisons, HadISST has been linearly 218 interpolated onto the CTL horizontal grid. Both the full data period (1870-2013) of HadISST and the two sub-periods, pre- and post-1979, are considered to account for long-term SST 
220 background and uncertainties induced by the late 1970s climate shift when evaluating the

221 different simulations in Section 3.

223 Table 2 details the main acronyms and the location of the different regions utilized for

224 computing the rainfall and SST indices used in this study. HadISST is used to evaluate the 225 mean annual cycle and interannual variability in observed SSTs of the Niño3.4, western 226 (wIOD) and eastern (eIOD) IOD regions. The Indian Rainfall (IR) index simulated by CTL 227 over the Indian subcontinent is evaluated against the All Indian Rainfall index (AIR; 228 Parthasarathy et al. 1995). The AIR index is an area-weighted average of 306 rain gauges 229 distributed across India from 1871 onwards and is frequently used to assess the relationships 230 between ISMR and Indo-Pacific SSTs (e.g., Boschat et al. 2011, 2012). The length of the 231 AIR time-series allows a fair and consistent comparison with our long coupled simulations, 232 but note that the use of a satellite-based IR instead of the AIR yields similar results if we 233 restrict our analysis to the post-1979 period for observations (not shown).

235 The variability and lead-lag relationships between the different times-series in both 236 observations and simulations are described by simple statistics, such as standard deviation and 237 Bravais-Pearson linear correlation in Section 3. A monthly linear trend is removed before 238 computing standard deviations and correlations from HadISST SSTs in order to avoid 239 contamination of the statistics by the global warming trend, which is absent from our $\mathrm{CO}_{2}-$ 240 fixed simulations.

242 The specific role of IOD and ISMR on Indo-Pacific climate variability and the relationships 243 between IOD and ISM are then compared in the presence and absence of ENSO through a 244 linear regression approach performed on CTL, FTPC and FTPC-obs experiments (Section 4). 
245 The standardized SON IOD and JJAS IR seasonal indices (see Table 2) are used in these

246 regression analyses. The regressed spatial anomalous patterns describe the monthly evolution

247 of water and energy cycles (rainfall, latent heat fluxes, and net shortwave radiations at the

248 surface), atmospheric circulation (850-hPa wind, 200-hPa velocity potential), and thermal

249 state of the ocean (SSTs and depth of the $20^{\circ} \mathrm{C}$ oceanic isotherm: $20 \mathrm{~d}$ hereafter) from June to

250 September, i.e. during the ISM. The statistical confidence of the results is evaluated by

251 comparing the slope of each regression to the $90^{\text {th }}$ percentile threshold value obtained by

252 regressing 1000 randomly perturbed time-series having mean and variance similar to the

253 original time-series onto the SON IOD / JJAS IR predictors.

254

255 To verify that the linear regression analysis does not hide any asymmetry between pIODs and 256 nIODs, a composite analysis based on the IOD index has also been performed. The results 257 reveal that the simulated pIOD and nIOD patterns are strongly symmetric with each other in 258 the presence and absence of ENSO (not shown), justifying the use of a linear regression 259 analysis to synthetically describe the IOD-ISM relationships in our simulations.

260

261

262

3) Model evaluation and statistical effects of Pacific SST nudging

263

264

\section{1) Annual mean climatology and variability}

265

266 The annual mean climatology and variability of monthly SSTs simulated by CTL are 267 evaluated against long-term SST observations between $40^{\circ} \mathrm{S}$ and $40^{\circ} \mathrm{N}$ (Fig. 1a-f). The 268 observed spatial distribution in annual mean SST climatology (Fig. 1a) is accurately captured 269 by the CTL (Fig. 1c), with a spatial pattern correlation of +0.98. In contrast with many 
AOGCMs without flux adjustments, the CTL has only a small cold tongue bias in the central

271 equatorial Pacific (Fig. 1e). However, the model errors remain significant with warm biases of $2721-3 \mathrm{~K}$ in the tropics, especially in the upwelling regions, and cold biases of $1-2 \mathrm{~K}$ in the mid273 latitudes (Fig. 1e).

The spatial correlation between the observed and CTL monthly SST variability (Fig. 1b,d) is +0.72 . This indicates fair simulation of the main observed SST variability pattern in the tropics and mid-latitudes. The CTL captures reasonably SST variability in the tropical Pacific despite largely confined to the equatorial belt and in the tropical Indian Ocean, except significant overestimation along the shores of Java and Sumatra (Fig. 1f) due to overactive boreal fall upwelling (Fischer et al. 2005; Terray et al. 2012). Elsewhere, the SST variability in CTL is slightly stronger than observed.

The suppression of ENSO variability in FTPC does not impact the mean SST state (Fig. 1g), but does reduce significantly the SST variability in the tropical Pacific by construction, but also in the extra-tropical Pacific and tropical Indian Oceans (Fig. 1h). This reduction in SST variability outside the tropical Pacific highlights the global nature of ENSO teleconnections, which are absent in FTPC. On the other hand, nudging toward an observed tropical Pacific SST climatology in FTPC-obs significantly decreases the warm SST bias everywhere (Fig. 1i), and SST variability is further decreased compared to CTL in the eastern equatorial Indian Ocean and the subtropical Atlantic Ocean (Fig. 1j). This demonstrates that a significant part 291 of the warm SST mean biases in the Indian and Atlantic sectors has a remote origin in the tropical Pacific. Changes in the Indian Ocean mean state induced by tropical Pacific SST bias correction also implies that FTCP-obs may be more complex than FTPC to analyze the direct

294 influence of ENSO suppression on the two-way IOD-ISM relationships. 
Figure 2a,e shows the mean annual cycle and variability of observed and simulated monthly IR (Table 2). The CTL captures realistically the rainfall annual cycle over India. However, the simulated IR index is affected by a dry bias during ISM (Fig. 2a), due to a too equatorward position of the boreal summer ITCZ and a delayed ISM onset (Prodhomme et al. 2014, 2015). Despite of this mean dry bias, monthly IR variability is well captured by CTL (Fig. 2e). Surprisingly, the suppression of ENSO variability in FTPC does not significantly modify the mean annual cycle and variability of IR (Fig. 2a,e) despite the strong relationship between ENSO and ISM variability in the CTL (see below). Compared to CTL and FTPC, FTPC-obs improves the IR annual cycle with a peak in June as observed (Fig. 2a). However, the dry IR bias during ISM persists in FTPC-obs, suggesting that reducing the warm SST bias over the Indian Ocean is not sufficient to shift the ITCZ northward. FTPC-obs also simulates enhanced IR variability in June, suggesting a more variable ISM onset (Fig. 2e). Since these changes are not shared by FTPC and FTPC-obs, they partly relate to the rectification of the mean state of the Indian Ocean induced by the correction of the Pacific SST biases in FTPC-obs. The same statistical analysis is performed for the Niño3.4, wIOD, and eIOD SST indices

314 (Table 2). The CTL reasonably captures the SST mean annual cycle over the three regions 315 (Fig. 2b-d). Its main weaknesses include a timing error in the Niño3.4 region, with coldest 316 SSTs peaking in boreal fall instead of boreal winter. This bias is related to the misrepresented eastern Pacific cold tongue seasonal cycle in the SINTEX model, as in most AOGCMs (Li and Xie 2014). The CTL struggles also in capturing the observed SST magnitude. The warm bias in annual mean tropical SSTs (Fig. 1e) is prominent during boreal spring, while it is 
reduced from late boreal summer to fall over the three regions (Fig. 2b-d), and even of reversed sign in the eIOD pole during boreal fall. This highlights a strong seasonal dependency of model SST biases. In particular, the CTL experiences a cold SST bias in the eIOD pole from mid-June to late November, reaching up to $1 \mathrm{~K}$ during September (Fig. 2d).

324 This longstanding cold bias in SINTEX and other AOGCMs originates from too shallow 325 equatorial thermocline and too intense evaporation in the eastern Indian Ocean during boreal 326 summer and fall (Fischer et al. 2005; Cai et al. 2013). The CTL also reasonably captures the 327 timing of the observed peaks of variability in the Niño3.4 and eIOD regions (Fig. 2f,h), as 328 well as the relatively flat SST variability observed in the wIOD region (Fig. 2g). Main model 329 biases concern SST variability that is underestimated in the Niño3.4 region during the ENSO 330 peak (Fig. 2f) and largely overestimated in the eIOD pole during the IOD peak (Fig. 2h). The 331 latter error is associated with too strong wind-thermocline-SST and wind-evaporation-SST 332 feedbacks simulated by the SINTEX model in the eIOD pole during boreal fall (Fischer et al. 333 2005; Terray et al. 2012). Additional analyses have also been done to further evaluate the SST 334 variability simulated in the Indian Ocean. The main results (not shown) indicate first a better 335 agreement between the HadISST data and the CTL over the wIOD pole when considering the 336 recent observed decades, hence substantial observational uncertainties resulting from the 337 scarcity of in situ data before 1979 and/or changes in the low-frequency variability of the 338 Indian Ocean. Second, the strongest observed and simulated SST variability does peak during 339 boreal fall when considering the traditional IOD index, consistent with the literature.

341 The mean annual cycle of the Niño3.4 SSTs is almost the same in CTL and FTPC (Fig. 2b) 342 because tropical Pacific SSTs of the latter are nudged toward the daily SST climatology of the 343 former. It is also similar in the Indian Ocean despite of the absence of ENSO in FTPC (Fig. $3442 \mathrm{c}-\mathrm{d})$. On the other hand, by construction, FTPC-obs almost perfectly corrects the CTL timing 
and magnitude errors in the Niño3.4 region (Fig. 2f). It also largely corrects the boreal spring

346 warm SST bias of the two IOD poles (Fig. 2c-d), which therefore partly originates from 347 remote errors in the annual cycle of tropical Pacific SSTs. However, FTPC-obs fails (as

348 FTPC) at correcting the cold bias of boreal fall eIOD SSTs (Fig. 2d). This persistent bias is 349 thus relatively independent from simulated ENSO variability and the mean SST background 350 errors in the tropical Pacific in our simulations and have, thus, a local origin.

SST variability is logically suppressed in the tropical Pacific in the absence of ENSO (Fig. 2f) and also systematically reduced over the two IOD poles by a rather constant factor (Fig. $2 \mathrm{~g}$ -

$354 \mathrm{~h})$. This corroborates the hypothesis that some IODs may be triggered or amplified by ENSO 355 (Gualdi et al. 2003; Annamalai et al. 2003; Yu and Lau 2005; Luo et al. 2010). However, the 356 eIOD SST variability simulated by FTPC and FTPC-obs remains strong and even higher than 357 the observed one. This is partly related to the model mean state bias (e.g. Fig. 2d), but 358 confirms that IODs exist without ENSO in our two nudged experiments as in previous 359 modeling studies (Fischer et al. 2005; Behera et al. 2006; Luo et al. 2010; Santoso et al. 2012; 360 Wang et al. 2016). This also suggests that eIOD may be more fundamental than wIOD for 361 explaining IOD life cycle, as recently suggested in the observations (Zhao and Nigam 2015).

\section{3) ENSO-IOD-ISM relationships}

365 The CTL ability in representing both the synchronous and delayed relationships of the

366 ENSO-IOD-ISM system is evaluated through a lead-lag correlation analysis between the 367 Niño3.4, wIOD, eIOD SST, and ISMR indices. Figure 3a shows the observed and CTL368 simulated lead/lag relationships between ISMR (i.e., JJAS IR: see Table 2) and monthly 369 Niño3.4 SSTs from one year before (year -1) to one year after (year +1$)$ the year of the ISM 
season (year 0) and the Niño3.4 SST autocorrelation. While with weaker intensity (partially

371 due to the longer length of CTL), the CTL correctly captures the synchronous negative 372 observed relationship, with warm SST anomalies in the eastern and central Pacific during the 373 developing stage of ENSO associated with negative ISMR anomalies, and vice versa for cold 374 SST anomalies. This negative relationship slowly disappears with the decaying stage of 375 ENSO and the observed correlations between ISMR and Niño3.4 SST during year +1 are 376 well-reproduced by CTL. This good model skill mainly results from accurate timing of ENSO 377 since the shape of the simulated Niño3.4 SST autocorrelation is similar to that observed (Fig. 3a). At longer leads/lags, the ISMR-ENSO relationship is weak and mostly insignificant in both observations and CTL.

The observed relationship between SON SSTs from the wIOD and eIOD poles and monthly Niño3.4 SSTs (Fig. 3b) indicates that pIODs occur frequently during El Niños and nIODs during La Niñas, consistent with previous studies. This is reflected by positive (negative) correlations observed during year 0 and the first half of year +1 in the wIOD (eIOD) pole.

385 Such opposition of phase is captured by the CTL only when excluding the $5^{\circ} \mathrm{S}-5^{\circ} \mathrm{N}$ band 386 prior to form the wIOD SST index because of too intense pIODs in the SINTEX AOGCM 387 (see Table 2).

We finally address the CTL ability in simulating the two-way relationships between IOD and ISM by showing lead/lag correlations between ISMR and monthly wIOD and eIOD SSTs 391 (Fig. 3c). These relationships are weak and noisy in both observations and CTL. The exception is the negative correlation between ISMR and monthly wIOD and eIOD SSTs during boreal fall and winter of year 0 and during year +1 . This suggests that above- (below-) normal ISMRs are followed several months later by negative (positive) tropical Indian Ocean 
395 SST anomalies. This negative relationship appears first in the western Indian Ocean during

396 boreal summer (Fig. 3c). This is consistent with the strong relationship between ENSO and 397 both ISM and Indian Ocean variability, especially the basin-wide warming (cooling) of the 398 Indian Ocean following El Niños (La Niñas).

4) IOD and ISM influences on Indo-Pacific variability

403 Despite errors in the eIOD SST magnitude, the CTL reasonably captures the variability of the ENSO-IOD-ISM system during year 0 (Fig. 3). This gives confidence in utilizing the SINTEX model to disentangle ENSO-induced and pure IOD-ISM relationships. This section clarifies these pure relationships, as well as remote connections with the Western North Pacific (WNP) by comparing the CTL to the two no-ENSO experiments.

\section{1) IOD influence on ISM and Indo-WNP variability}

The SON eIOD SST index is used for assessing the influence of IODs on interannual variability in the Indo-WNP sector. This index is preferred to the traditional IOD index

413 because the IOD variability is mainly driven by the eIOD variability in both the presence and 414 absence of ENSO in our modeling framework. It is worth noting that the results shown 415 hereafter are similar when using the traditional IOD index (not shown). This demonstrates 416 that the eIOD index is a good proxy of IODs in our modeling framework, with positive SST 417 anomalies in the eIOD pole during boreal fall corresponding to nIODs.

419 We first focus on the springtime initiation of IODs by showing the regression maps of April- 
May (AM) SST, latent heat flux, rainfall and low-level wind anomalies onto the normalized

421 SON eIOD SST index for CTL (Fig. 4a-b), FTPC (Fig. 4c-d), and FTPC-obs (Fig. 4e-f). In all simulations, positive eIOD SST anomalies during boreal fall are lead by significant boreal spring ocean-atmosphere anomalies over the South-East Indian Ocean (SEIO). The AM

424 regressed fields suggest that a regional coupled mode involving positive (negative) SST and 425 rainfall anomalies and cyclonic (anticyclonic) low-level circulation anomalies over the SEIO 426 is the main trigger of nIODs (pIODs). This atmospheric pattern is similar to that described as a key trigger of many IODs in the presence of ENSO in both observations and AOGCMs (Gualdi et al. 2003; Li et al. 2003; Annamalai et al. 2003; Terray et al. 2007). Our two noENSO experiments demonstrate that such precursor atmospheric pattern may exist even without ENSO, as a pure regional mode or linked to tropical-extra-tropical interactions in the 431 Indian Ocean (Terray et al. 2005, 2007). This coupled pattern of variability is sufficient to initiate a positive wind-evaporation-SST feedback off the coast of Sumatra and Java and to trigger westerly wind anomalies (and a wind-thermocline-SST feedback) along the equatorial 434 Indian Ocean during IOD events (Fig. 4), confirming their fundamental roles in IOD onset (Li 435 et al. 2003; Spencer et al. 2005). Interestingly, this boreal spring coupled mode is shifted a 436 few degrees southwestward in FTPC-obs, which has a colder Indian Ocean background mean 437 state than FTPC and CTL (Figs. 1g,i and 2c-d) due to the rectification of tropical Pacific SST 438 errors. This favors stronger low-level westerlies over the central equatorial Indian Ocean and 439 a stronger Somali jet off the African coast in FTPC-obs (Fig. 4f). As a result, evaporating 440 cooling (warming) is enhanced over the western equatorial Indian Ocean (SEIO) leading to 441 the emergence of a northwest-southeast dipole of SST anomalies in the tropical Indian Ocean 442 during boreal spring in FTPC-obs (Fig. 4e). Thus, IOD-like zonal SST patterns are nearly 443 symmetric as soon as boreal spring in FTPC-obs, while remain asymmetric until late June in 444 CTL and FTPC (see Fig. 5a-b). In addition to the strength of the low-level equatorial wind 
anomalies (Sun et al. 2014), the location of the regional ocean-atmosphere coupled mode and

446 the background SST mean state per se are also critical for the emergence of IOD-like SST 447 patterns during the onset phase of the IOD events.

The boreal summer evolution of IOD-related SST and 20d anomalies is described from June to September for the CTL and the two no-ENSO experiments (Figs. 5 and 6, respectively). The morphological differences between IODs in the different experiments rapidly weaken in early boreal summer (Fig. 5a-b,e-f,i-j), and the mechanisms explaining the evolution of IODrelated SST and 20d anomalies is very similar between the three experiments. During early

454 nIOD summers, significant positive SST anomalies are located off the coast of Sumatra and 455 Java (Fig. 5), and an equatorial downwelling Kelvin wave develops in the eastern equatorial 456 Indian Ocean (Fig. 6) in response to the westerly wind anomalies over the equatorial Indian 457 Ocean during boreal spring (Fig. 4). These equatorial subsurface anomalies rapidly affect the 458 thermocline along the coast of Sumatra. Subsequently, both the SST and 20d anomalies 459 originating from the eastern equatorial Indian Ocean progressively propagate westward and 460 intensify along the equator through Ekman convergence/divergence for peaking in 461 September-October (not shown). This mechanism highlights that the subsurface and coupled 462 dynamics over the SEIO are critical for IOD-like SST anomalies to develop (Li et al. 2003; 463 Terray et al. 2007; Wang et al. 2016), even in the absence of ENSO.

465 Contrary to this common mechanism, the morphology of IOD-related SST and 20d anomalies 466 also differs between the three experiments (Figs. 5 and 6). First, the magnitude and spatial 467 coverage of eIOD SST anomalies are greater in the CTL (Fig. 5a-d) than the FTPC (Fig. 5e468 h), while the overall 20d anomaly pattern is similar between these two experiments (Fig. 6a-d 469 and e-h, respectively), which also share the same background SST mean state (Fig. 1g). This 
indicates that ENSO amplifies IOD patterns at the surface but not in the subsurface, consistent

471 with the independence of the subsurface to ENSO reported by Rao et al. (2002). Second, there 472 are again significant differences between FTPC-obs and the two other experiments. In the 473 northern Indian Ocean, CTL and FTPC simulate significant negative SST anomalies 474 extending from the eastern Arabian Sea to the southern tip of India (Fig. 5a-h) and significant 475 negative 20d anomalies in the eastern Arabian Sea and Bay of Bengal (Fig. a-h). This 476 suggests that these regional anomalies are mostly independent from ENSO in our modeling 477 framework. On the other hand, FTPC-obs simulates broader zonal IOD SST patterns (Fig. 5i478 1) than CTL (Fig. 5a-d) and FTPC (Fig. 5e-h), and boreal summer 20d anomalies that are 479 positive in the Bay of Bengal and SEIO and negative mainly in the South-West Indian Ocean 480 (Fig. 6i-1). In the southern Indian Ocean, negative 20d anomalies simulated by CTL and 481 FTPC in the $5^{\circ}-25^{\circ} \mathrm{S}-60^{\circ}-100^{\circ} \mathrm{E}$ region during early summer, progressively move westward, 482 but remain systematically weak along the African coast during the ISM (Fig. 6a-h). By 483 contrast, those simulated by FTPC-obs are more intense, spreading from the eastern coast of 484 Tanzania to $\sim 100^{\circ} \mathrm{E}$ throughout the ISM, with greatest anomalies located north of Madagascar 485 (Fig. 6i-1). Such differences between FTPC-obs and the two other experiments point toward 486 the need to better assess the role of the mean SST background on both SST and 20d 487 variability in the Indian Ocean in order to understand the IOD variability.

489 The influence of IODs on boreal summer rainfall and atmospheric circulation over the Indo490 WNP sector is now explored for the different experiments (Figs. 7-8). During nIOD years, the 491 three experiments simulate early summer positive rainfall anomalies in the central and eastern 492 equatorial Indian Ocean (Fig. 7a-b,e-f,i-j) consistent with enhanced convection over the SEIO 493 during boreal spring (Fig. 4b,d,f). This rainfall center is much more intense and widespread 494 spatially in the presence of ENSO. In the CTL, it extends up to Indonesia and is associated 
with strong surface wind convergence (Fig. 7a-d) and upper-level wind divergence (Fig. 8a-d)

496 there, consistent with a strong modulation of the Walker circulation associated with growing 497 La Niñas. On the other hand, the rainfall center and associated circulation anomalies remain confined over the eIOD pole during early summer in the absence of ENSO (Figs. 7e-1 and 8e-

499 1). It is shifted southwestward and less regionally confined in FTPC-obs, which simulates 500 amplified surface wind convergence and upper-level wind divergence (Figs. 7i-1 and 8i-1) than

501 FTPC (Fig. 7e-h and 8e-h). The three experiments struggle to produce negative (positive) rainfall anomalies over the western equatorial Indian Ocean in response to nIODs (pIODs),

503 which contrasts with the traditional view that the main atmospheric response to IOD 504 variability during boreal summer is over the equatorial Indian Ocean. Such zonal rainfall 505 dipole is simulated only during the mature phase of IODs (Figs. 7d,h,l and 8d,h,l). It is again 506 much stronger in the CTL than the two no-ENSO experiments. This relates to stronger 507 equatorial westerly wind anomalies simulated in the presence of ENSO due to stronger convection over the eIOD pole and the Maritime Continent. This also relates to the presence of negative 200-hPa velocity potential anomalies over most of the Indian sector induced by La

510 Niñas.

512 In addition, the three experiments simulate a meridional dipole in rainfall that persists 513 throughout most of the ISM, with positive (negative) anomalies in the equatorial (northern) 514 Indian Ocean during nIOD years (Fig. 7), and vice versa during pIOD years. This is consistent 515 with the modulation of the local Hadley cell seen in the absence of ENSO, with 200-hPa 516 divergence over the warm eIOD pole and 200-hPa convergence and compensating subsidence 517 over the North Indian Ocean during some months of nIOD summers (Figs. 8e-1). These 518 meridional upper-level circulation anomalies are greater in FTPC than FTPC-obs, consistent 519 with the more significant and persistent surface and subsurface cold temperature anomalies 
over the North Indian Ocean in FTPC (Fig. 5e-h) than FTPC-obs (Fig. 5i-1). However, this

521 anomalous Hadley cell remains locked over oceanic regions surrounding the Indian 522 subcontinent in both no-ENSO experiments and is masked in the CTL, resulting in weak and 523 barely significant IR anomalies most of the time in all experiments. Therefore, the poor 524 influence of IODs on ISMR in the presence of ENSO (Figs. 3c and 7a-d) does not result from 525 counter effects between ENSO and IOD in our modeling framework. While the IOD influence 526 on ISM involves changes in the meridional circulation over the Indian sector (Ashok et al. 527 2001, 2004; Gadgil et al. 2004; Behera et al. 2005; Ashok and Saji 2007; Ummenhofer et al. 528 2011), it is rather weak in our no-ENSO experiments, suggesting that other modes account for 529 ISM variability.

531 Last but not least, significant differences are found between the CTL and the two no-ENSO experiments over the Indo-WNP sector. In the presence of ENSO, a quasi-zonal rainfall mode

533 links the eIOD-Indonesian sector with the western tropical and equatorial Pacific throughout 534 the ISM, with a strong upper-level divergence over the former and convergence over the latter 535 during nIOD summers (Figs. 7a-d and 8a-d). This mode involves strong changes in the 536 Walker circulation and is driven by El Niño-to-La Niña transitions since rainfall anomalies in 537 the western tropical and equatorial Pacific establish during the preceding boreal winter (not 538 shown). The connection between the Indian and WNP sectors significantly differ in the 539 absence of ENSO. The rainfall pattern simulated by FTPC and FTPC-obs over the tropical 540 Indian Ocean is embedded in a late summer cross-equatorial rainfall quadrupole pattern 541 extending over the Indo-WNP sector (Fig. 7g and 7k-1). This evidences strong remote effects 542 of IODs in the absence of ENSO. This IOD-induced rainfall mode is accompanied by robust 543 changes in the atmospheric circulation. Its low-level nIOD signature corresponds to cyclonic 544 wind and positive rainfall anomalies over the SEIO and the WNP traditionally reported during 
545 growing La Niñas and linked to the TBO (e.g., Wang et al. 2003; Li et al. 2006). Its upper-

546 level nIOD signature reveals strong divergence anomalies (negative 200-hPa velocity 547 potential anomalies) extending from the SEIO to the WNP that grow and intensify until 548 August in FTPC (Fig. 8e-g) and September in FTPC-obs (Fig. 8i-1). This confirms the

549 significant forcing of the Indian Ocean can have on the WNP variability (e.g., Li et al. 2006) 550 and complements the results by Chowdary et al. (2011) who show that removing the tropical 551 Indian Ocean variability within partially decoupled global experiments dramatically weakens 552 the WNP interannual variability.

\section{2) ISM influence on Indian Ocean and Indo-WNP variability}

556 Figures 9 and 10 show the regression maps of surface temperature (i.e., SST over ocean and 557 skin temperature over land), 850-hPa wind, rainfall, and 200-hPa velocity potential anomalies 558 from June to September onto the normalized ISMR anomalies for the CTL and FTPC. Results 559 for FTPC-obs are similar to FTPC, hence not shown. Consistent with Fig. 3a-b and the 560 literature (see Introduction), above-normal ISMRs occur during growing La Niñas in the

561 CTL. This is reflected by significant surface cooling over the central and eastern tropical 562 Pacific, strengthened low-level easterlies over the equatorial Pacific (Fig. 9a-d) and a 563 westward shift in the Walker circulation (Fig. 10a-d), with positive rainfall anomalies over 564 India and an equatorial band extending from the eIOD pole to the Maritime Continent. Over 565 the Indian Ocean, the atmospheric response to a above-normal ISMs (and to the La Niña 566 conditions) involves a seesaw between the Somali and the eastern Indian Ocean cross567 equatorial winds with an enhanced Somali jet and monsoon flux over the central Arabian Sea 568 throughout the ISM (Fig. 9a-d). This strengthens (weakens) the climatological monsoon 
569 fluxes in the western (eastern) Indian Ocean, hence promotes the emergence of a nIOD-like

570 SST pattern during the course of boreal summer (Fig. 9a-d).

572 Without ENSO, above-normal ISM exerts also a significant and robust influence on Indian

573 Ocean SSTs, but the SST anomalous pattern does not exhibit any similarity with IOD (Fig.

$5749 \mathrm{e}-\mathrm{h})$. This suggests that ENSO plays a prominent role in governing the seesaw relationship in

575 the inter-hemispheric transport and the resulting SST IOD-like pattern over the Indian Ocean 576 in CTL and confirms the weak intrinsic relationship between IOD and ISM (Fig. 9e-h). In

577 FTPC, cold SSTs are found over the Arabian Sea, but not over the western equatorial Indian 578 Ocean from July to September (Fig. 9f-h). They primarily result from enhanced evaporative 579 cooling in response to the stronger monsoon flux (Fig. 9e-h) and increased cloud cover 580 associated with the enhanced monsoon rainfall (Fig. 10e-h). The Arabian Sea is thus an 581 important source of moisture for ISMR, consistent with previous studies (Izumo et al. 2008; 582 Boschat et al. 2011; Levine and Turner 2013; Prodhomme et al. 2014).

584 Finally, without ENSO, active convection and diabatic heating over India induce a strong 585 signal to the East over the WNP and the China Sea (Fig. 10e-h). This forms a strong zonal 586 dipole in rainfall and atmospheric circulation, with $200-\mathrm{hPa}$ divergence over India and the 587 Arabian Sea opposing to 200-hPa convergence and decreased rainfall over the WNP. The 588 large convection-induced diabatic heating over India generates a large-scale divergent 589 anomalous circulation at upper levels in the north subtropics associated with strong low-level 590 anticyclonic circulation anomalies over the WNP and off-equatorial easterly wind anomalies 591 over the China Sea and the Bay of Bengal (Fig. 9e-h). The close similarity of this atmospheric 592 pattern with the numerical results of Rodwell and Hoskins (2001) suggests that this 593 atmospheric response is mainly driven by the east-west differential heating induced by the 
594 ISMR anomalies through the planetary-scale upper-level divergent circulation and a Kelvin-

595 wave response on the equatorward portion of the WNP anticyclone. In turn, the strong off596 equatorial low-level easterly anomalies over the Bay of Bengal constructively interact with

597 the southwesterly wind anomalies over the Arabian Sea and increase significantly the 598 moisture convergence toward the Indian subcontinent (Fig. 9e-h).

599

600 Thus, our no-ENSO experiments complement the traditional view that strong (weak) WNP 601 monsoon (ISM) occurs during developing El Niños, and reversely during decaying El Niños 602 (Wang et al. 2001; Chou et al. 2003; Boschat et al. 2011; Prodhomme et al. 2015; Ratna et al. 603 2016). In FTPC, this rainfall dipole is mainly driven by atmospheric internal variability that 604 can develop without ENSO and even in the absence of strong SST anomalies in the WNP or 605 the Indian Ocean (Fig. 9e-h).

606

607 Importantly, this subtropical ISM-WNP rainfall dipole clearly differs from the rainfall 608 quadrupole simulated during ENSO-free IOD years, which is more oceanic and equatorially 609 confined (Figs. 7-8). This means that two distinct modes of variability connect the Indian and 610 the Western Pacific sectors in the absence of ENSO: a subtropical zonal mode driven by 611 ISMR and associated diabatic heating (Fig. 10e-h), and a cross-equatorial quadrupole mode 612 influenced by IOD variability and coupled ocean-atmosphere dynamics over the SEIO (Figs. 613 7-8). 
618 Partial ocean-atmosphere decoupling experiments are used to discuss the influence of ISMR 619 and IOD variability over the Indo-WNP sector in the absence of ENSO. This approach 620 complements observation-based studies that often utilize linear regression techniques to 621 remove ENSO's influence and stand-alone atmospheric simulations that do not account for 622 air-sea feedbacks in monsoon regions.

624 A control simulation is first analyzed to ensure realistic representation of the ENSO-IODISM system, a difficult task for current AOGCMs (e.g., Cai et al. 2009; Terray et al. 2012; Sperber et al. 2013; Shukla and Huang 2016b). Despite biased magnitude of eIOD SSTs, the

627 control reasonably captures many observed features of the ENSO-IOD-ISM system (Figs. 1628 3). This gives confidence in utilizing the SINTEX AOGCM for untangling ENSO-induced and no-ENSO IOD-ISM relationships. Two no-ENSO experiments, FTPC and FTPC-obs, are then run with SST variability removed in the tropical Pacific through nudging toward the SST

631 climatology from the control and observations, respectively. The signal shared by the two no632 ENSO experiments is a robust response to ENSO removing, while inter-experiment 633 differences result from differential mean SST background induced by the tropical Pacific SST 634 bias rectification in FTPC-obs only.

635

636 Surprisingly, the model mean state (annual mean and mean annual cycle) is very similar 637 between CTL and FTPC outside the nudging region (Figs. 1-2). Two hypotheses may explain 638 such similarity. First, the SST climatology and annual cycle over the tropical Pacific may 639 include the rectification of the Pacific mean state induced by the ENSO variability in the 640 CTL. By this mechanism, any rectification of the mean state due to ENSO can still be present 641 in FTPC. The important differences in mean state between FTPC and FTPC-obs are 642 consistent with such interpretation. Second, changes in the interannual variability do not 
necessary induce changes in the mean state, and reversely. This is especially true in current

644 coupled models that struggle in capturing the observed positive skewness of ENSO (Masson et al. 2012), hence possible cancelling effects between El Niños and La Niñas on the mean state of our century-long control run may also explain the similarity.

648 While ENSO suppression significantly reduces SST variability in the Indian Ocean, it does 649 not prevent IODs to exist (Figs. 2,4-6). This confirms the importance of the subsurface and 650 local ocean-atmosphere feedbacks over the tropical SEIO for IOD trigger and evolution 651 (Fischer et al. 2005; Behera et al. 2006; Terray et al. 2007; Wang et al. 2016). The greater 652 similarity of the onset of IODs between CTL and FTPC compared to FTP-OBS suggests that 653 this phase is more influenced by the correction of the Pacific and Indian mean state than by 654 the removal of ENSO.

655

656 Both no-ENSO experiments simulate a significant boreal summer meridional dipole in 657 rainfall during IOD years that also exists in the presence of ENSO. The strong diabatic 658 heating associated with enhanced rainfall over the eIOD pole during nIOD summers 659 modulates the local Hadley circulation (Figs. 7-8), inducing negative rainfall anomalies in the 660 northern Indian Ocean during boreal summer. The reverse prevails during pIOD summers. 661 Such changes in the local Hadley circulation are attenuated in the presence of ENSO because 662 global-scale changes in the Walker circulation dominate. However, the IOD influence on 663 ISMR barely emerges from noise in all experiments. This may be a model bias since the CTL 664 and the two nudged experiments overestimate the eIOD SST variability and underestimate the 665 wIOD SST variability compared to observations (Fig. 2g-h). Apart from this modest influence 666 on ISMR, pure IODs promote a late summer cross-equatorial quadrupole rainfall pattern 667 linking the North Indian Ocean with the WNP (Figs. 7-8), consistent with the WNP 
monsoon-warm Indian Ocean interactions described in previous studies (Wang et al. 2003; Li et al. 2006). This rainfall patterns greatly differs from that simulated in the presence of ENSO, confirming potential opposite effects between IOD and ENSO (e.g., Ashok et al. 2001; Pepler et al. 2014).

The way around, the interannual variability of ISM does not influence IODs during their developing stage when ENSO is removed in our modeling framework (Fig. 9e-h). This contrasts with the control and observations for which positive (negative) ISMR anomalies tend to favor nIODs (pIODs) (Figs. 3c and 9a-d). This result is consistent with the fact that above-normal ISMs can co-occur with either nIODs (e.g., Loschnigg et al. 2003; Kulkarni et al. 2007; Webster and Hoyos 2010) or pIODs (Annamalai et al. 2003; Krishnan and Swapna 2009). On the other hand, the two no-ENSO experiments highlight a significant forcing of the enhanced monsoon circulation onto the Arabian Sea SSTs (Fig. 10), suggesting a passive role of the Indian Ocean in the absence of ENSO. This is in line with Shukla (1987), but contrasts with many recent observational studies (Boschat et al. 2011; Shukla and Huang 2016a). It is 683 thus of utmost importance to determine the model dependency of this result.

Finally, convection and diabatic heating associated with above-normal ISM induce strong upper-level convergence, subsidence, and low-level anticyclonic anomalies in the WNP, 687 forming hence a strong subtropical dipole in rainfall and atmospheric circulation (Fig. 10). 688 While this dipole and associated atmospheric circulation are weaker in the absence of ENSO, 689 this mode can be interpreted as a pure response to enhanced ISMR (Rodwell and Hoskins 690 2001) with no active role of SST anomalies in the absence of ENSO. This suggests that ISM 691 has an active rather than a passive role in tropical variability. Again, it is important to confirm 692 the model dependency of this result, which has important implications for ISM predictability. 
694 Despite not perfect, our partially ocean-atmosphere decoupled experiments clearly 695 demonstrate that the IOD-ISM relationship is weak even in the absence of ENSO, letting 696 room for two independent modes of variability to develop in the Indo-WNP sector: a purely 697 atmospheric subtropical zonal mode driven by convection and diabatic heating over India and 698 a quadrupole tropical atmospheric mode driven by warm ocean-atmosphere interactions over 699 the SEIO and IOD.

700

701 Additional work is clearly required to test the robustness and model dependency of these 702 results, which may shed new light on the mechanisms underlying the ISM variability. Our 703 next step is to focus on IOD triggering with and without ENSO in a multi-model framework.

704

705

\section{Acknowledgments}

708 This work was funded by the Earth System Science Organization, Ministry of Earth Sciences, 709 Government of India under Monsoon Mission (Project No. MM/SERP/CNRS/2013/INT710 10/002 Contribution \#MM/PASCAL/RP/07. The simulations were performed using French

711 HPC resources from GENCI-IDRIS supercomputers. We thank the three anonymous 712 reviewers for their helpful comments. 


\section{References}

714

715

716

717

718

Annamalai H, R Murtugudde, J Potemra, SP Xie, P Liu, B Wang (2003) Coupled dynamics over the Indian Ocean: Spring initiation of the zonal mode. Deep-Sea Res II, 50:23052330

Ashok K, Z Guan, T Yamagata (2001) Impact of the Indian Ocean dipole on the relationship between the Indian monsoon rainfall and ENSO. Geophys Res Lett 26:4499-4502

Ashok K, Z Guan, T Yamagata (2003) A look at the relationship between the ENSO and the Indian Ocean dipole. J Meteor Soc Japan, 81:41-56

Ashok K, Z Guan, NH Saji, T Yamagata (2004) Individual and combined influences of ENSO and the Indian Ocean dipole on the Indian summer monsoon. J Clim 17:3141-3155

Ashok K, NH Saji (2007) On impacts of ENSO and Indian Ocean dipole events on the subregional Indian summer monsoon rainfall. Natural Hazards 42-2:273-285

Ashrit RG, KR Kumar, KK Kumar (2001) ENSO-Monsoon relationships in a greenhouse warming scenario. Geophys Res Let $28: 1727-1730$

Behera SK, R Krishnan, T Yamagata (1999) Unusual ocean-atmosphere conditions in the tropical Indian Ocean during 1994. Geophys Res Lett 26(19):3001-3004

Behera SK, JJ Luo, S Masson, P Delecluse, S Gualdi, A Navarra, T Yamagata (2005) Paramount impact of the Indian Ocean dipole on the East African short rains: a CGCM study. J Clim 18:4514-4530

Behera SK, JJ Luo, S Masson, SA Rao, H Sakuma, T Yamagata (2006) A CGCM study on the interaction between IOD and ENSO. J Clim 19:1608-1705

Boschat G, P Terray, S Masson (2011) Interannual relationships between Indian summer monsoon and Indo-Pacific coupled modes of variability during recent decades. Clim Dyn 37:1019-1043 
Boschat G, P Terray, S Masson (2012) Robustness of SST teleconnections and precursory patterns associated with the Indian summer monsoon. Clim Dyn 38:2143-2165

Bracco A, F Kucharski, F Molteni (2005) Internal and forced modes of variability in the Indian Ocean. Geophys Res Lett 32, L12707, doi:10.1029/2005GL023154

Cai W, A Sullivan, T Cowan T (2009) Climate change contributes to more frequent consecutive positive Indian Ocean dipole events. Geophys Res Lett 36, L23704, doi:10.1029/2009GL040163

Cai W, XT Zheng, E Weller, M Collins, T Cowan, M Lengaigne, W Yu, T Yamagata (2013) Projected response of the Indian Ocean dipole to greenhouse warming. Nature Geosci 6:999-1007

Chen TC (2003) Maintenance of Summer Monsoon Circulations: A Planetary-Scale Perspective. J Clim 16:2022-2037

Cherchi and Navarra (2013) Influence of ENSO and of the Indian Ocean dipole on the Indian summer monsoon variability. Clim Dyn 41:81-103

Chou C, JY Tu, JY Yu (2003) Interannual variability of the western North Pacific summer monsoon: differences between ENSO and non-ENSO years. J Clim 16:2275-2287

Chowdary JS, SP Xie, JJ Luo, J Hafner, S Behera, Y Masumoto, T Yamagata (2011) Predictability of Northwest Pacific climate during summer and the role of the tropical Indian Ocean. Clim Dyn 36:607-621

Clark CO, JE Cole, PJ Webster (2000) Indian Ocean SST and Indian summer rainfall: predictive relationships and their decadal variability. J Clim 13:2503-2519

Compo G, P Sardeshmukh (2010) Removing ENSO-related variations from the climate records. J Clim 23:1957-1978

761 Dommenget D (2011) An objective analysis of the observed spatial structure of the tropical Indian Ocean SST variability. Clim Dyn 36:2129-2145 
763 Drbohlav HKL, S Gualdi, A Navarra (2007) A diagnostic study of the Indian Ocean dipole mode in El Niño and non-El Niño years. J Clim 20:2961-2977

765

766

767

768

Du Y, SP Xie (2008) Role of atmospheric adjustments in the tropical Indian Ocean warming during the 20th century in climate models. Geophys Res Let 35, L08712, doi:10.1029/2008GL033631

Fischer AS, P Terray, P Delecluse, S Gualdi, E Guilyardi (2005) Two independent triggers for the Indian Ocean dipole/zonal mode in a coupled GCM. J Clim 18:3428-3449

Gadgil S, PN Vinayachandran, PA Francis, S Gadgil (2004) Extremes of the Indian summer monsoon rainfall, ENSO and equatorial Indian Ocean oscillation. Geophys Res Lett 31, L12213, doi:10.1029/2004GL019733

Gadgil S, M Rajeevan, R Nanjundiah (2005) Monsoon prediction - why yet another failure? Curr Sci 84:1713-1719

Gadgil S, M Rajeevan, PA Francis (2007) Monsoon variability: links to major oscillations over the equatorial Pacific and Indian oceans. Curr Sci 93:182-194

Gualdi S, E Guilyardi, A Navarra, S Masina, P Delecluse (2003) The interannual variability in the tropical Indian Ocean as simulated by a CGCM. Clim Dyn 20:567-582

Guan Z, K Ashok, T Yamagata (2003) Summertime response of the tropical atmosphere to the Indian Ocean dipole sea surface temperature anomalies. J Meteorol Soc Japan, $81: 533-561$

Ihara C, Y Kushnir, MA Cane, VH De La Peña (2007) Indian summer monsoon rainfall and its link with ENSO and Indian Ocean climate indices. Int J Clim 27:179-187

Ihara C, Y Kushnir, MA Cane (2008) Warming trend of the Indian Ocean SST and Indian Ocean dipole from 1880 to 2004. J Clim 21:2035-2046 
Izumo T, C de Boyer Montégut, JJ Luo, SK Behera, S Masson, T Yamagata (2008) The role of the western Arabian Sea upwelling in Indian monsoon rainfall variability. J Clim $21: 5603-5623$

Izumo T, J Vialard, M Lengaigne, C de Boyer Montégut, SK Behera, JJ Luo, S Cravatte, S Masson, T Yamagata (2010) Influence of the state of the Indian Ocean Dipole on the following year's El Niño. Nature Geoscience 3:168-172

792

793

794

795

Izumo T, M Lengaigne, J Vialard, JJ Luo, T Yamagata, G Madec (2014) Influence of Indian Ocean dipole and Pacific recharge on following year's El Niño: interdecadal robustness. Clim Dyn 42:291-310

Jourdain NC, M Lengaigne, J Vialard, T Izumo, Sen Gupta A (2016) Further insights on the influence of the Indian Ocean dipole on the following year's ENSO from observations and CMIP5 models. J Clim 29:637-658

Krishnan R, M Mujumdar, V Vaidya, KV Ramesh, V Satyan (2003) The abnormal Indian summer monsoon of 2000. J Clim 16:1177-1194

Krishnan R, P Swapna (2009) Significant influence of the boreal summer monsoon flow on the Indian Ocean response during dipole events. J Clim 22:5611-5634

Krishnaswamy J, S Vaidyanathan, B Rajagopalan, M Bonell, M Sankaran, RS Bhalla, S Badiger (2015) Non-stationary and non-linear influence of ENSO and Indian Ocean dipole on the variability of Indian monsoon rainfall and extreme rain events. Clim Dyn 45:175-184

Kulkarni A, SS Sabade, RH Kripalani (2007) Association between extreme monsoons and the dipole mode over the Indian subcontinent. Meteorol Atm Phys 95: 255-268

Kumar KK, B Rajagopalan, M Cane (1999) On the weakening relationship between the Indian monsoon and ENSO. Science 284:2156-2159 
810 Levine RC, AG Turner, D Marathayil, GM Martin (2013) The role of northern Arabian Sea surface temperature biases in CMIP5 model simulations and future projections of Indian summer monsoon rainfall. Clim Dyn 41:155-172

813 Li G, SP Xie (2014) Tropical biases in CMIP5 multimodel ensemble: the excessive Equatorial Pacific cold tongue and double ITCZ problems. J Clim 27:1765-1780

Li T, B Wang, CP Chang, YS Zhang (2003) A theory for the Indian Ocean dipole-zonal mode. J Atmos Sci 60:2119-2135

Li T, P Liu, X Fu, B Wang, GA Meehl (2006) Spatiotemporal structures and mechanisms of the Tropospheric Biennial Oscillation in the Indo-Pacific warm ocean regions. J Clim 19:307 0-3087

Loschnigg J, GA Meehl, PJ Webster, JM Arblaster, GP Compo (2003) The Asian monsoon, the tropospheric biennial oscillation and the Indian Ocean dipole in the NCAR CSM. J Clim 16:2138-2158

Luo JJ, S Masson, S Behera, S Shingu, T Yamagata (2005) Seasonal climate predictability in a coupled OAGCM using a different approach for ensemble forecasts. J Clim 18 :4474-

Luo JJ, R Zhang, S Behera, Y Masumoto, FF Jin, R Lukas, T Yamagata (2010) Interactions between El Nino and extreme Indian Ocean dipole. J Clim 23: 726-742

Madec G (2008) NEMO ocean engine. Note du Pôle de modélisation, Institut Pierre-Simon Laplace (IPSL), France. No 27. ISSN No 1288-1619

830 Masson S, P Terray, G Madec, JJ Luo, T Yamagata, K Takahashi (2012) Impact of intra-daily SST variability on ENSO characteristics in a coupled model. Clim Dyn 39:681-707

832 Meehl GA, JM Arblaster (2002) Indian monsoon GCM sensitivity experiments testing tropospheric biennial oscillation transition conditions. J Clim 15:923-944 
834 Meehl GA, JM Arblaster, J Loschnigg (2003) Coupled ocean-atmosphere dynamical processes in the tropical Indian and Pacific Oceans and the TBO. J Clim 16:2138-2158

836 Murtugudde R, JP McCreary Jr, AJ Busalacchi (2000) Oceanic processes associated with anomalous events in the Indian Ocean with relevance to 1997-1998. J Geophys Res $105: 3295-3306$

Park HS, JCH Chiang, BR Lintner, JG Zhang (2010) The delayed effect of major El Niño events on Indian monsoon rainfall. J Clim 23:932-946

841 Parthasarathy B, AA Munot, DR Kothawale (1995) All India monthly and seasonal rainfall series: 1871-1993. Theor Appl Climatol 49:217-224

843 Pepler A, B Timbal, C Rakich, A Coutts-Smith (2014) Indian Ocean dipole overrides ENSO's influence on cool season rainfall across the eastern seaboard of Australia. J Clim

Pillai PA, K Mohankumar (2010) Individual and combined influence of El Niño-Southern Oscillation and Indian Ocean dipole on the tropospheric biennial oscillation. Q J R Meteorol Soc 136:297-304

Pokhrel S, HS Chaudhari, SK Saha, A Dhakate, RK Yadav, K Salunke, S Mahapatra, SA Rao (2012) ENSO, IOD and Indian summer monsoon in NCEP climate forecast system. Clim Dyn 39:2143-2165

852 Prodhomme C, P Terray, S Masson, T Izumo, T Tozuka, T Yamagata (2014) Impacts of Indian Ocean SST biases on the Indian monsoon: as simulated in a global coupled model. Clim Dyn 42:271-290

855 Prodhomme C, P Terray, S Masson, G Boschat, T Izumo (2015) Oceanic factors controlling 856 the Indian summer monsoon onset in a coupled model. Clim Dyn 44:977-1002 Indian monsoon: a new perspective. Mon Wea Rev 116:558-568 
Rao SA, SK Behera, Y Masumoto, T Yamagata (2002) Interannual subsurface variability in the Tropical Indian Ocean with a special emphasis on the Indian Ocean Dipole. DeepSea Res 49:1549-1572

Rasmusson EM, TH Carpenter (1983) The relationship between eastern equatorial Pacific sea surface temperatures and rainfall over India and Sri Lanka. J Clim 111:517-528

Ratna SB, A Cherchi, PV Joseph, SK Behera, B Abish, S Masina (2016) Moisture variability over the Indo-Pacific region and its influence on the Indian summer monsoon rainfall. Clim Dyn 46:949-965

Rayner NA, DE Parker, EB Horton, CK Folland, LV Alexander, DP Rowell, EC Kent, A Kaplan (2003) Global analyses of sea surface temperature, sea ice, and night marine air temperature since the late nineteenth century. J Geophys Res 108, doi:10.1029/2002JD002670

Reverdin G, D Cadet, D Gutzler (1986) Interannual displacements of convection and surface circulation over the equatorial Indian Ocean. Q J R Meteorol Soc 112:43-46

Reynolds RW, TM Smith, C Liu, DB Chelton, KS Casey, MG Schlax (2007) Daily highresolution blended analyses for sea surface temperature. J Clim 20:5473-5496

Rodwell MJ, BJ Hoskins (2001) Subtropical anticyclones and summer monsoons. J Clim $14: 3192-3211$

Roeckner E, G Baüml, L Bonaventura, R Brokopf, M Esch, M Giorgetta, S Hagemann et al (2003) The atmospheric general circulation model ECHAM5: Part 1: model description. Max-Planck-Institut für Meteorologie, MPI-Report 353, Hamburg

Roxy M, S Gualdi, HKL Drbohlav, A Navarra (2010) Seasonality in the relationship between El Niño and Indian Ocean Dipole. Clim Dyn 37:221-236

Roxy MK, K Ritika, P Terray, S Masson (2014) The curious case of Indian Ocean warming. J Clim 27:8501-8509 
Roxy MK, K Ritika, P Terray, R Murutugudde, K Ashok, BN Goswami (2015) Drying of Indian subcontinent by rapid Indian Ocean warming and a weakening land-sea thermal gradient. Nature Communications, 6:7423, doi:10.1038/ncomms8423

Saji NH, BN Goswami, PN Vinayachandran, T Yamagata (1999) A dipole mode in the tropical Indian Ocean. Nature 401:360-363

Saji NH, T Yamagata (2003) Possible impacts of Indian Ocean dipole mode events on global climate. Clim Res 25:151-169

Santoso A, MH England, W Cai (2012) Impact of Indo-Pacific feedback interactions on ENSO dynamics diagnosed using ensemble climate simulations. J Clim 25:7743-7763

Shukla J (1987) Interannual variability of monsoons. In Monsoons Fein JS, Stephens PL (eds). John Wiley and Sons:339-463

Shukla RP, B Huang (2016a) Interannual variability of the Indian summer monsoon associated with the air-sea feedback in the northern Indian Ocean. Clim Dyn 46:19771990

Shukla RP, B Huang (2016b) Mean state and interannual variability of the Indian summer monsoon simulation by NCEP CFSv2. Clim Dyn, doi:10.1007/s00382-015-2808-6

900 Sikka DR (1980) Some aspects of the large-scale fluctuations of summer monsoon rainfall 901 over India in relation to fluctuations in the planetary and regional scale circulation parameters. Proc Indian Acad Sci Earth Planet Sci 89:179-195

Spencer H, RT Sutton, JM Slingo, JM Roberts, E Black (2005) The Indian Ocean climate and dipole variability in the Hadley centre coupled GCMs. J Clim 18:2286-2307

905 Sperber KR, H Annamalai, IS Kang, A Kitoh, A Moise, A Turner, B Wang, T Zhou (2013) The Asian summer monsoon: an intercomparison of CMIP5 vs. CMIP3 simulations of the late 20th century. Clim Dyn 41:2711-2744 
Sun S, Y Fang, Tana, B Liu (2014) Dynamical mechanisms for asymmetric SSTA patterns associated with some Indian Ocean Dipoles. J Geophys Res Oceans, doi: 10.1002/2013JC009651

Terray P, P Delecluse, S Labattu, L Terray (2003) Sea surface temperature associations with the late Indian summer monsoon. Clim Dyn 21:593-618

Terray P, S Dominiak, P Delecluse (2005) Role of the southern Indian Ocean in the transitions of the monsoon-ENSO system during recent decades. Clim Dyn 24:169-195

Terray P, F Chauvin, H Douville (2007) Impact of southeast Indian Ocean sea surface temperature anomalies on monsoon-ENSO dipole variability in a coupled oceanatmosphere model. Clim Dyn 28:553-580

Terray P, K Kamala, S Masson, G Madec, AK Sahai, JJ Luo, T Yamagata (2012) The role of the intra-daily SST variability in the Indian monsoon variability and monsoon-ENSOIOD relationships in a global coupled model. Clim Dyn 39:729-754

Terray P, S Masson, C Prodhomme, MK Roxy, KP Sooraj (2016) Impacts of Indian and Atlantic oceans on ENSO in a comprehensive modeling framework. Clim Dyn 46:2507-2533

Timmermann R, H Goosse, G Madec, T Fichefet, C Ethe, V Duliere (2005) On the representation of high latitude processes in the ORCA-LIM global coupled sea iceocean model. Ocean Model 8(1-2):175-201

Ummenhofer CC, A Sen Gupta, PR Briggs, MH England, PC McIntosh, GA Meyers, MJ Pook, MR Raupach, JS Risbey (2011) Indian and Pacific ocean influences on southeast Australian drought and soil moisture. J Clim 24:1313-1336

Valcke S (2006) OASIS3 user guide (prism_2-5). PRISM support initiative report No 3, 64 pp Walker GT (1924) Correlations in seasonal variations of weather. I. A further study of world weather. Mem Indian Meteorol Dep 24:275-332 
933 Wang B, R Wu, KM Lau (2001) Interannual variability of the Asian summer monsoon: contrast between the Indian and the Western North Pacific-East Asian monsoons. J Clim 14:4073-4090

Wang B, R Wu, T Li (2003) Atmosphere-warm ocean interaction and its impacts on AsianAustralian monsoon variation. J Clim 16:1195-1211

938 Wang B, I Kang, J Lee (2004) Ensemble simulations of Asian-Australian monsoon variability by 11 AGCMs. J Clim 17:803-818

Wang B, QH Ding, XH Fu, IS Kang, K Jin, J Shukla, F Doblas-Reyes (2005) Fundamental challenge in simulation and prediction of summer monsoon rainfall. Geophys Res Lett 32, L15711, doi:10.1029/2005GL022734

Wang H, R Murtugudde, A Kumar (2016) Evolution of Indian Ocean dipole and its forcing mechanisms in the absence of ENSO. Clim Dyn, doi:10.1007/s00382-016-2977-y

945 Webster PJ, Moore AM, Loschnigg JP, Leben RR (1999) Coupled ocean-atmosphere dynamics in the Indian Ocean during 1997-98. Nature 401:356-360

947 Webster PJ, Hoyos CD (2010) Beyond the spring barrier? Nature Geoscience 3:152-153

948 Wu RG, BP Kirtman (2004) Impacts of the Indian Ocean on the Indian summer monsoonENSO relationship. J Clim 17:3037-3054

950 Yamagata T, SK Behera, SA Rao, Z Guan, K Ashok, HN Saji (2002) The Indian Ocean 951 dipole: a physical entity. CLIVAR Exchanges 24:15-18

952 Yang J, Q Liu, SP Xie, Z Liu, L Wu (2007) Impact of the Indian Ocean SST basin mode on

953 the Asian summer monsoon. Geophys Res Lett 34, L02708, $954 \quad$ doi:10.1029/2006GL028571

955 Yasunari T (1991) The monsoon year - a new concept of the climatic year in the tropics. Bull Am Meteorol Soc 72:1331-1338 
957 Yu JY, KM Lau (2005) Contrasting Indian Ocean SST variability with and without ENSO 958 influence: a coupled atmosphere-ocean GCM study. Meteorol Atmos Phys 90:179-191

959 Zhao Y, S Nigam (2015) The Indian Ocean dipole: a monopole in SST. J Clim 28:3-19

960 Zhou Q, Duan W, M Mu, R Feng (2015) Influence of positive and negative Indian Ocean 961 dipoles on ENSO via the Indonesian throughflow: results from sensitivity experiments. $962 \quad$ Adv Atm Sci 32:783-793

963 
965

966 Table 1: $\quad$ Summary and acronyms of the different coupled simulations performed with 967 the SINTEX-F2 AOGCM. The column "Setup" describes the differences between the 968 different experiments. See Fig. 1h,j for the definition of the tropical Pacific domain where 969 nudging is performed in FTPC and FTPC-obs.

970

971 Table2: Acronym, peak season and location of the area-averaged rainfall and SST 972 indices used for assessing ISMR, ENSO and IOD variability in Sections 3 and 4. An Indian 973 Rainfall (IR) times-series over the Indian subcontinent defines ISMR, Niño3.4 SSTs is used 974 as an ENSO index and, finally, the traditional wIOD and eIOD regions, as defined by Saji et 975 al. (1999), represent the IOD variability. See text for further details. 
978 Figure 1: (a) Annual mean SST climatology estimated from the HadISST data over the 979 1870-2013 period. (b) Standard deviation of monthly SSTs after removing the mean annual 980 cycle and the monthly linear trend due to global warming from the HadISST data. See Section 9812.2 for details. (c-d) Same as (a-b) but for the CTL. (e-f) Same as (a-b) but for CTL biases 982 against the HadISST data. (g-h) and (i-j) Same as (a-b) but for differences between the two no-ENSO experiments and the CTL. Only biases/differences that are significant at the 95\% confidence level according to a Student t test for SST mean state and a chi-square test for SST 985 variability are shown in panels e to j. The dark blue area over the tropical Pacific in the panels $986 \mathrm{~h}$ and $\mathrm{j}$ is the region where SSTs have been nudged toward SST climatology in the FTPC and $987 \quad$ FTPC-obs experiments.

Figure 2: $\quad$ (a) Mean annual cycle of monthly Indian rainfall for the 1871-2013 AIR data, 990 the CTL, and the two no-ENSO experiments. (b-d) Same as (a) but for monthly SSTs over the 991 Niño3.4 region, and the western and the eastern IOD poles, respectively. The 1870-2013 992 HadISST data is used for observations. (e) Same as (a), but for monthly standard deviations of 993 Indian rainfall. (f-h) Same as (b-d) but for monthly standard deviations of SST anomalies. The 994 observed SST indices in panels $\mathrm{f}$ to $\mathrm{h}$ have been detrended to remove the global warming 995 trend before estimating the standard deviations. See Table 2 for acronyms and index 996 locations.

998 Figure 3: (a) Lead-lag correlations between ISMR and monthly Niño3.4 SSTs for the 999 1871-2013 AIR-HadISST observations and the CTL (black and blue solid lines, 1000 respectively). The dotted lines correspond to observed and CTL-simulated Niño3.4 SST 
autocorrelation computed between December-January (DJ) Niño3.4 SSTs and monthly

1002 Niño3.4 SSTs. (b) Same as (a) but for lead-lag correlations between monthly Niño3.4 SSTs and SON SSTs from the western (solid lines) and eastern (dotted lines) IOD poles. (c) Same as (a) but between ISMR and monthly SSTs from the western (solid lines) and eastern (dotted lines) IOD poles. The monthly trend of observed SST variability is removed as in Fig. 1 to 1006 foster direct comparisons with our $\mathrm{CO}_{2}$-fixed simulations. Lead-lag correlations are computed 1007 for a 3-yr window from one year before (year -1) to one year after $(y e a r+1)$ the year of the 1008 ISM season (year 0). The blue, green and pink vertical bands symbolize the ISM, IOD, and ENSO peaks, respectively. Correlation values outside the limit of the two pink lines are significant at the $90 \%$ confidence level according to a Pearson test.

Figure 4: $\quad$ (a) April-May bi-monthly SST (shadings; K) and latent heat flux (blue and red 1013 contours for negative and positive anomalies, respectively; contours every $2 \mathrm{~W} \cdot \mathrm{m}^{-2}$ ) 1014 anomalies regressed onto normalized boreal fall (i.e., SON) eIOD SST anomalies for the CTL 1015 experiment. Positive latent heat flux anomalies warm the ocean. Black contours and purple 1016 dots show SST and latent heat flux anomalies significant at the $90 \%$ confidence level 1017 according to a bootstrap test, respectively. See Section 2.2 for details on the bootstrap test and 1018 Table 2 for the location of the eIOD index. (b) Same as (a) but for rainfall (shadings; mm.day ${ }^{-}$ $1019^{1}$ ) and 850-hPa wind (vectors; $\mathrm{m}^{-\mathrm{s}^{-1}}$ ) anomalies for the CTL experiment. Black contours and 1020 purple vectors show rainfall and $850-\mathrm{hPa}$ wind anomalies significant at the $90 \%$ confidence 1021 level, respectively. (c-d) Same as (a-b) but for the FTPC experiment. (e-f) Same as (a-b) but 1022 for the FTPC-obs experiment.

1024 Figure 5: July to September monthly SST anomalies regressed onto normalized boreal 1025 fall (i.e., SON) eIOD SST anomalies for the (a-d) CTL, (e-h) FTPC, and (i-l) FTPC-obs 
experiments. Positive values correspond to warm SSTs. Black contours are anomalies

1027 significant at the $90 \%$ confidence level according to a bootstrap test.

Figure 6: $\quad$ Same as Fig. 5 but for 20 d (i.e., depth of $20^{\circ} \mathrm{C}$ isotherm) anomalies. Positive values correspond to a deep thermocline.

Figure 7: Same as Fig. 5 but for monthly rainfall (shadings; mm.day ${ }^{-1}$ ) and 850-hPa wind (vectors; m. $\mathrm{s}^{-1}$ ) anomalies for the (a-d) CTL, (e-h) FTPC, and (i-l) FTPC-obs experiments. Black contours are significant rainfall anomalies and purple vectors are significant $850-\mathrm{hPa}$ wind anomalies, both at the $90 \%$ confidence level according to a bootstrap test.

Figure 8: $\quad$ Same as Fig. 5 but for monthly 200-hPa velocity potential (shadings; $10^{6} \mathrm{~m}^{2} . \mathrm{s}^{-}$ ${ }^{1}$ ) anomalies for the (a-d) CTL, (e-h) FTPC, and (i-l) FTPC-obs experiments. Black contours are significant $200-\mathrm{hPa}$ velocity potential anomalies at the $90 \%$ confidence level according to a bootstrap test. Positive 200-hPa velocity potential anomalies correspond to abnormal upper1041 level mass flux convergence.

1043 Figure 9: July to September monthly surface temperature (shadings; K) and 850-hPa 1044 wind (vectors; $\mathrm{m}^{-1}{ }^{-1}$ ) anomalies regressed onto normalized ISMR anomalies for the (a-d) CTL 1045 and (e-h) FTPC experiments. Black contours are significant surface temperature anomalies 1046 and purple vectors are significant $850-\mathrm{hPa}$ wind anomalies, both at the $90 \%$ confidence level 1047 according to a bootstrap test.

1049 Figure 10: Same as Fig. 9 but for monthly rainfall (shadings, mm.day ${ }^{-1}$ ) and 200-hPa 1050 velocity potential (contours every $2 \times 10^{-6} \mathrm{~m}^{2} \cdot \mathrm{s}^{-1}$ ) anomalies for the (a-d) CTL and (e-h) FTPC 
1051 experiments. Black contours and purple dots are significant rainfall and 200-hPa velocity 1052 potential anomalies at the $90 \%$ confidence level according to a bootstrap test, respectively. 


\begin{tabular}{|c|c|c|c|}
\hline & $\begin{array}{c}\text { Integration } \\
\text { (years) }\end{array}$ & \multicolumn{2}{|c|}{ Setup } \\
\hline CTL & 210 & \multicolumn{2}{|c|}{ Full ocean-atmosphere coupling } \\
\hline FTPC & 110 & \multirow{2}{*}{$\begin{array}{l}\text { Decoupled } \\
\text { tropical Pacific } \\
\text { by nudging } \\
\text { toward an SST } \\
\text { climatology }\end{array}$} & $\begin{array}{c}\text { CTL SST } \\
\text { climatology }\end{array}$ \\
\hline FTPC-obs & 50 & & $\begin{array}{c}\text { OISST-v2 SST } \\
\text { climatology }\end{array}$ \\
\hline
\end{tabular}

1055 Table 1: Summary and acronyms of the different coupled simulations performed with the 1056 SINTEX-F2 AOGCM. The column "Setup" describes the differences between the different 1057 experiments. See Fig. 1h,j for the definition of the tropical Pacific domain where nudging is 1058 performed in FTPC and FTPC-obs. 
1061

1062

1063

1064

1065

1066

1067

1068

1069

1070

1071

1072

\begin{tabular}{|c|c|c|c|}
\hline & Season & \multicolumn{2}{|c|}{ Location } \\
\hline IR* $^{*}$ & JJAS & $5^{\circ} \mathrm{N}-25^{\circ} \mathrm{N}$ & $70^{\circ} \mathrm{E}-95^{\circ} \mathrm{E}$ \\
\hline Niño3.4 & DJ & $5^{\circ} \mathrm{S}-5^{\circ} \mathrm{N}$ & $170^{\circ} \mathrm{W}-120^{\circ} \mathrm{W}$ \\
\hline wIOD** & \multirow{2}{*}{ SON } & $10^{\circ} \mathrm{S}-10^{\circ} \mathrm{N}$ & $50^{\circ} \mathrm{E}-70^{\circ} \mathrm{E}$ \\
\cline { 1 - 1 } \cline { 3 - 4 } eIOD & & $10^{\circ} \mathrm{S}-\mathrm{Eq}$ & $90^{\circ} \mathrm{E}-110^{\circ} \mathrm{E}$ \\
\hline
\end{tabular}

* The Indian Rainfall (IR) times-series is computed from land points only in the specified domain.

** The $5^{\circ} \mathrm{S}-5^{\circ} \mathrm{N}$ band has been removed prior to compute the wIOD SST index in the simulations to exclude the strong intrusion of the eastern equatorial cold tongue in the western Indian Ocean simulated during simulated pIODs. See text for details.

Table 2: Acronym, peak season and location of the area-averaged rainfall and SST indices used for assessing ISMR, ENSO and IOD variability in Sections 3 and 4. An Indian Rainfall (IR) times-series over the Indian subcontinent defines ISMR, Niño3.4 SSTs is used as an ENSO index and, finally, the traditional wIOD and eIOD regions, as defined by Saji et al. (1999), represent the IOD variability. See text for further details. 
Annual mean climatology

(a) HadISST

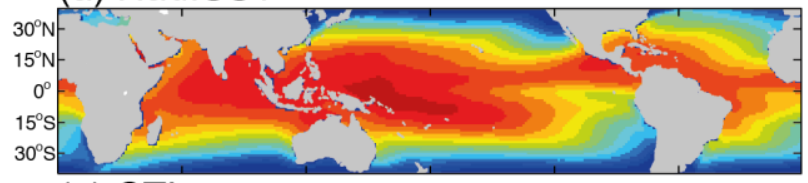

(c) CTL

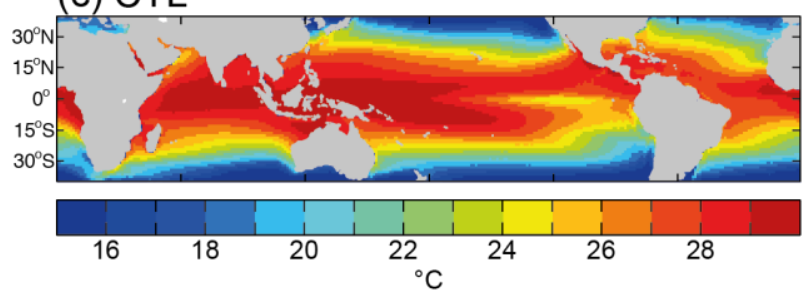

(e) CTL - HadISST

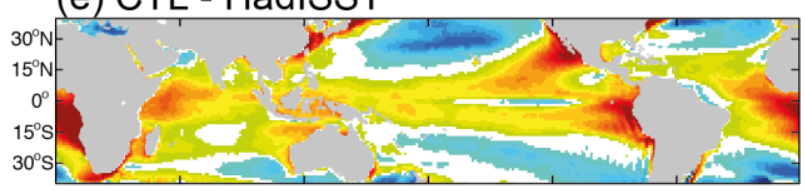

(g) FTPC - CTL

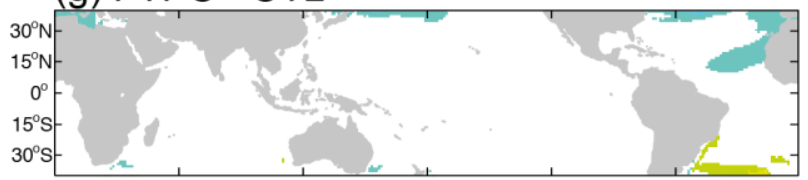

(i) FTPC-obs - CTL

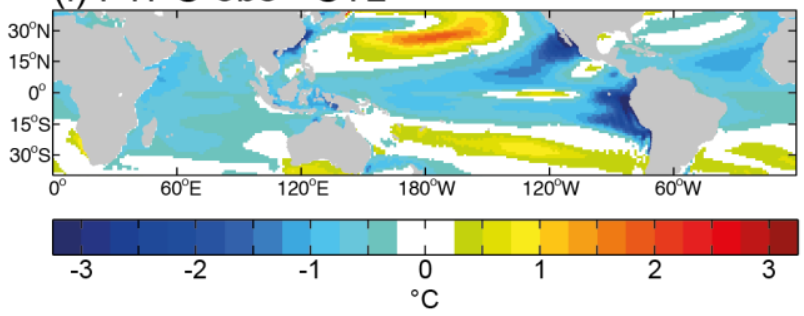

Variability

(b) HadISST

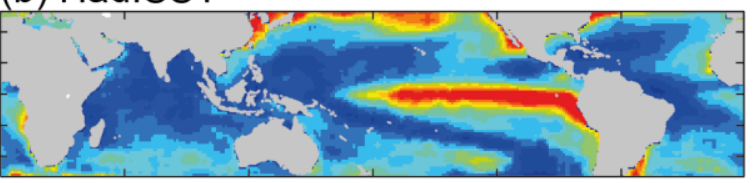

(d) CTL

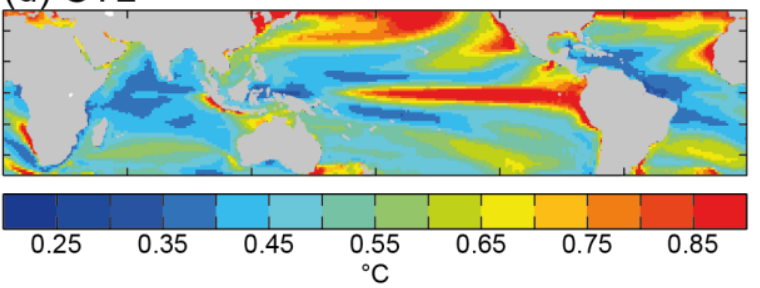

(f) CTL - HadISST

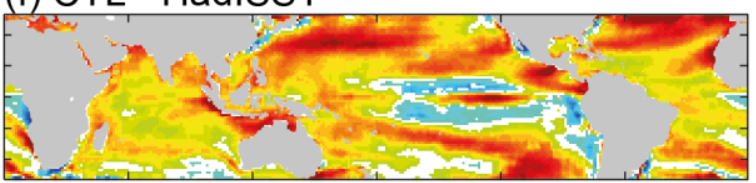

(h) FTPC - CTL

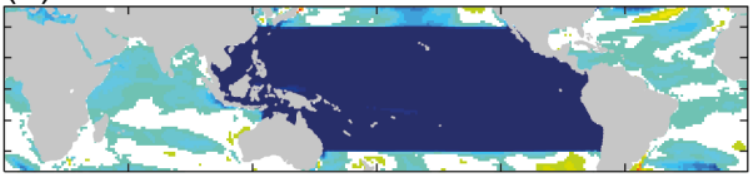

(j) FTPC-obs - CTL

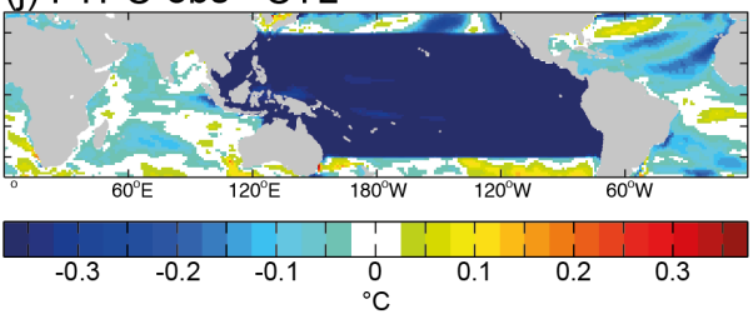

Figure 1: (a) Annual mean SST climatology estimated from the HadISST data over the 18702013 period. (b) Standard deviation of monthly SSTs after removing the mean annual cycle and the monthly linear trend due to global warming from the HadISST data. See Section 2.2 for details. (c-d) Same as (a-b) but for the CTL. (e-f) Same as (a-b) but for CTL biases against the HadISST data. (g-h) and (i-j) Same as (a-b) but for differences between the two no-ENSO experiments and the CTL. Only biases/differences that are significant at the $95 \%$ confidence level according to a Student t test for SST mean state and a chi-square test for SST variability are shown in panels e to $\mathrm{j}$. The dark blue area over the tropical Pacific in the panels $\mathrm{h}$ and $\mathrm{j}$ is the region where SSTs have been nudged toward SST climatology in the FTPC and FTPC-obs experiments. 
(a) IR (mm.day $\left.{ }^{-1}\right)$

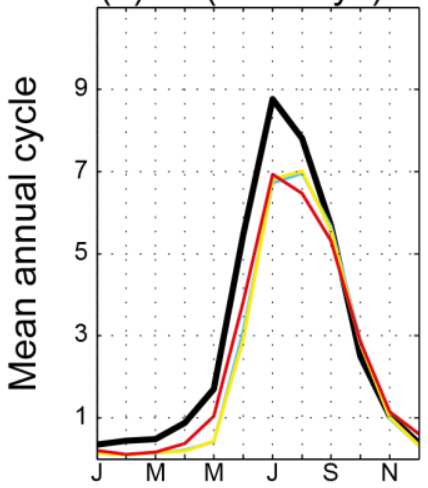

(e) IR (mm.day $\left.{ }^{-1}\right)$

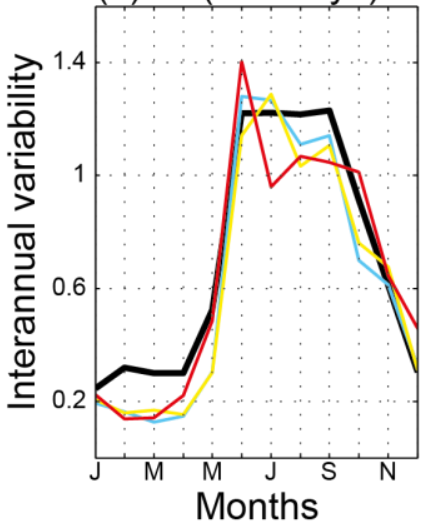

(b) Niño3.4 SST $\left({ }^{\circ} \mathrm{C}\right)$
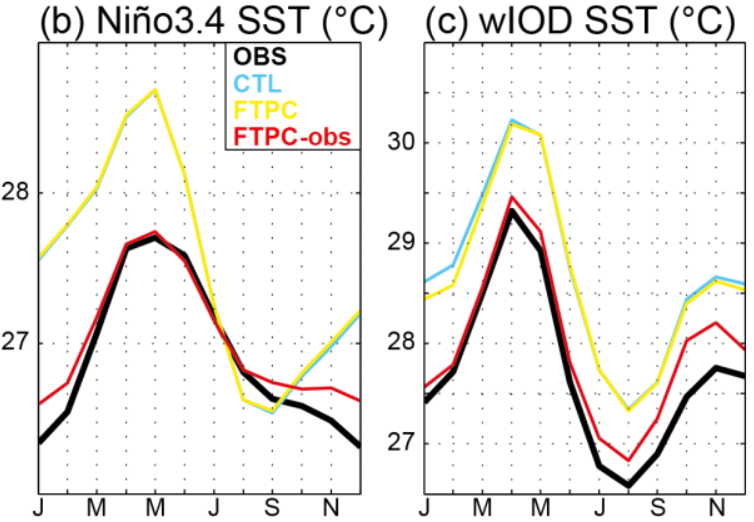

(f) Niño3.4 SST $\left({ }^{\circ} \mathrm{C}\right)$

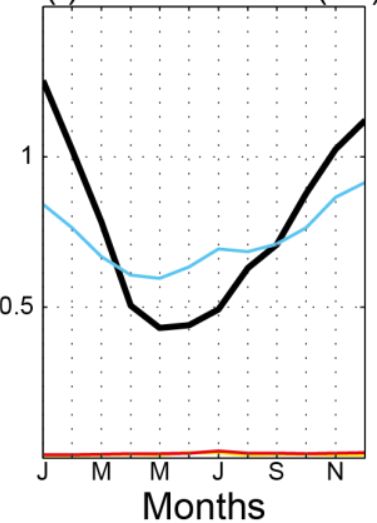

(g) wIOD SST $\left({ }^{\circ} \mathrm{C}\right)$

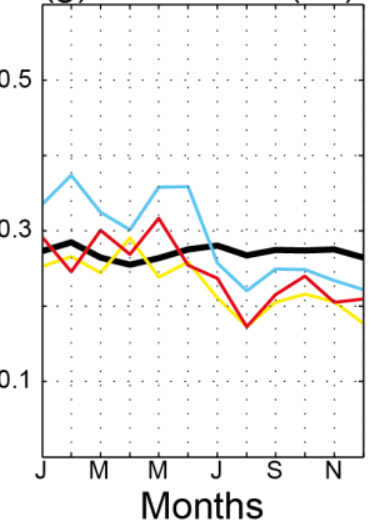

(d) eIOD SST $\left({ }^{\circ} \mathrm{C}\right)$

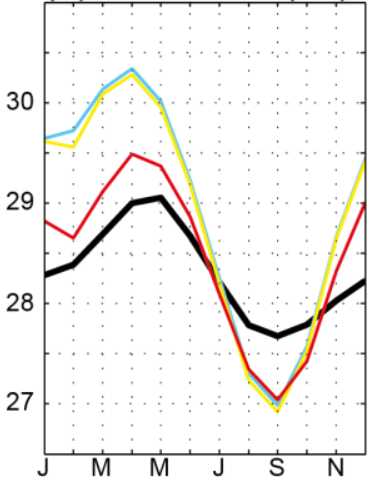

(h) elOD SST $\left({ }^{\circ} \mathrm{C}\right)$

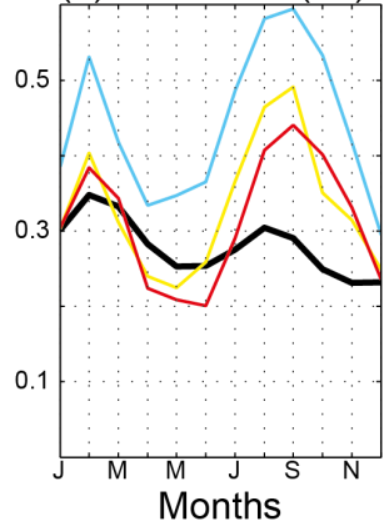

Figure 2: (a) Mean annual cycle of monthly Indian rainfall for the 1871-2013 AIR data, the CTL, and the two no-ENSO experiments. (b-d) Same as (a) but for monthly SSTs over the Niño3.4 region, and the western and the eastern IOD poles, respectively. The 1870-2013

1091 HadISST data is used for observations. (e) Same as (a), but for monthly standard deviations of Indian rainfall. (f-h) Same as (b-d) but for monthly standard deviations of SST anomalies. The observed SST indices in panels $f$ to $h$ have been detrended to remove the global warming trend before estimating the standard deviations. See Table 2 for acronyms and index locations. 
(a) ISMR (JJAS) \& mthly Niño3.4 SST

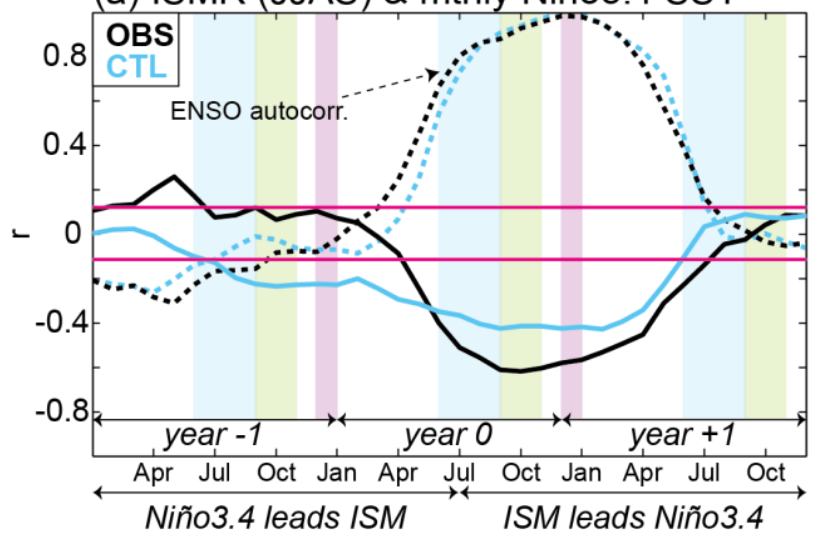

(b) SON w/elOD SST \& mthly Niño3.4 SST

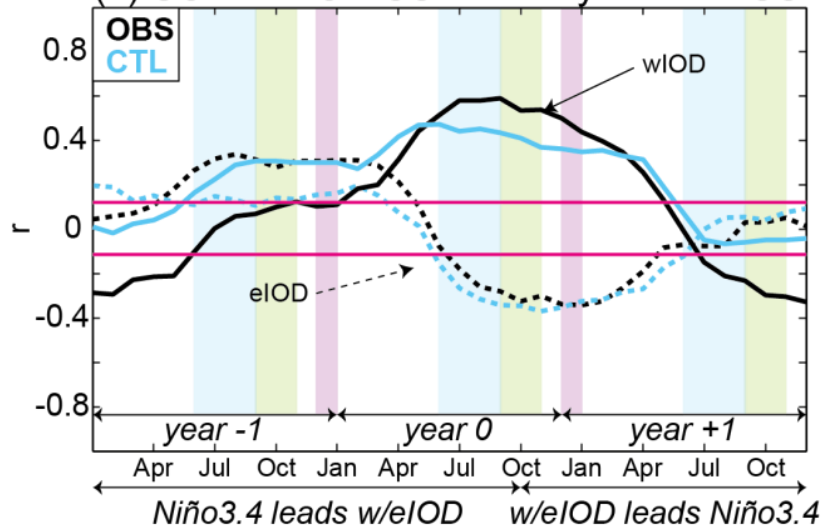

(c) ISMR (JJAS) \& mthly w/eIOD SST

Figure 3: (a) Lead-lag correlations between ISMR and monthly Niño3.4 SSTs for the 18712013 AIR-HadISST observations and the CTL (black and blue solid lines, respectively). The dotted lines correspond to observed and CTL-simulated Niño3.4 SST autocorrelation computed between December-January (DJ) Niño3.4 SSTs and monthly Niño3.4 SSTs. (b) Same as (a) but for lead-lag correlations between monthly Niño3.4 SSTs and SON SSTs from the western (solid lines) and eastern (dotted lines) IOD poles. (c) Same as (a) but between ISMR and monthly SSTs from the western (solid lines) and eastern (dotted lines) IOD poles. The monthly trend of observed SST variability is removed as in Fig. 1 to foster direct comparisons with our $\mathrm{CO}_{2}$-fixed simulations. Lead-lag correlations are computed for a 3-yr window from one year before (year -1) to one year after $($ year +1$)$ the year of the ISM season (year 0). The blue, green and pink vertical bands symbolize the ISM, IOD, and ENSO peaks, respectively. Correlation values outside the limit of the two pink lines are significant at the $90 \%$ confidence level according to a Pearson test. 


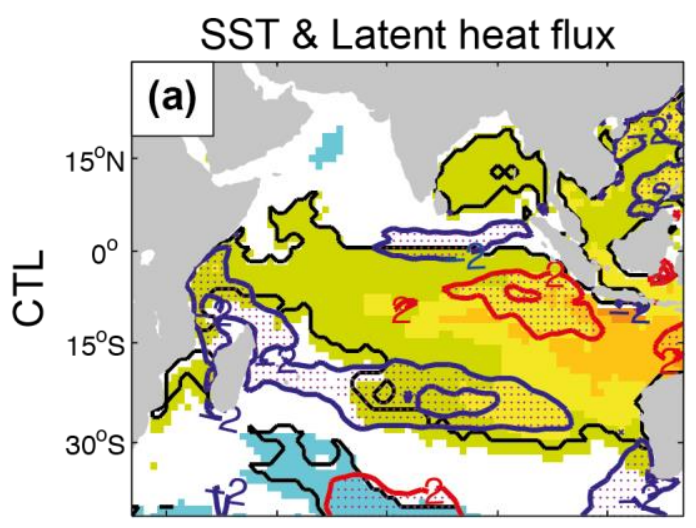

Rainfall \& 850-hPa wind
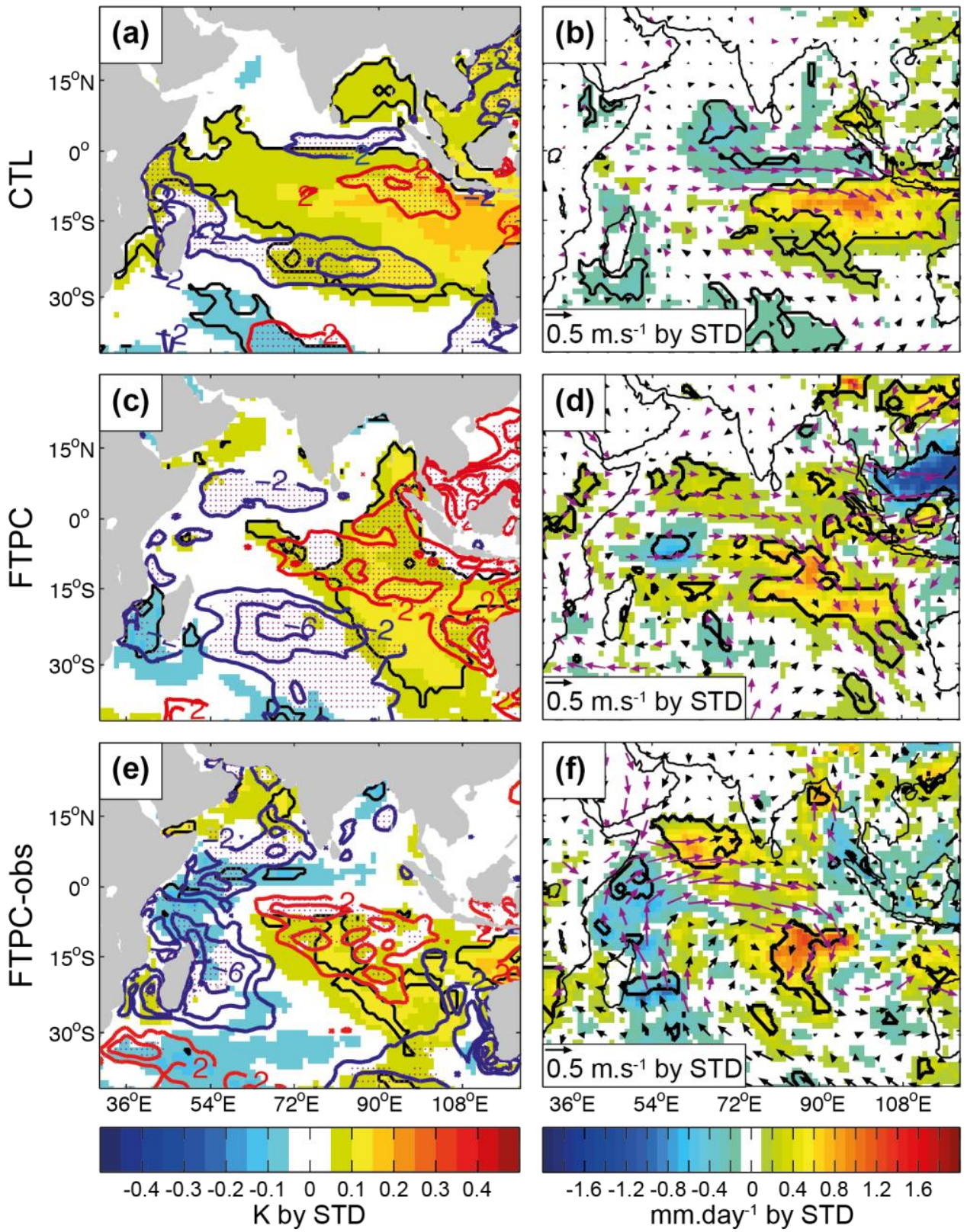

Figure 4: (a) April-May bi-monthly SST (shadings; K) and latent heat flux (blue and red contours for negative and positive anomalies, respectively; contours every $2 \mathrm{~W} \cdot \mathrm{m}^{-2}$ ) anomalies regressed onto normalized boreal fall (i.e., SON) eIOD SST anomalies for the CTL experiment. Positive latent heat flux anomalies warm the ocean. Black contours and purple dots show SST and latent heat flux anomalies significant at the $90 \%$ confidence level according to a bootstrap test, respectively. See Section 2.2 for details on the bootstrap test and Table 2 for the location of the eIOD index. (b) Same as (a) but for rainfall (shadings; mm.day ${ }^{-}$ ${ }^{1}$ ) and $850-\mathrm{hPa}$ wind (vectors; $\mathrm{m} . \mathrm{s}^{-1}$ ) anomalies for the CTL experiment. Black contours and purple vectors show rainfall and $850-\mathrm{hPa}$ wind anomalies significant at the $90 \%$ confidence level, respectively. (c-d) Same as (a-b) but for the FTPC experiment. (e-f) Same as (a-b) but for the FTPC-obs experiment. 

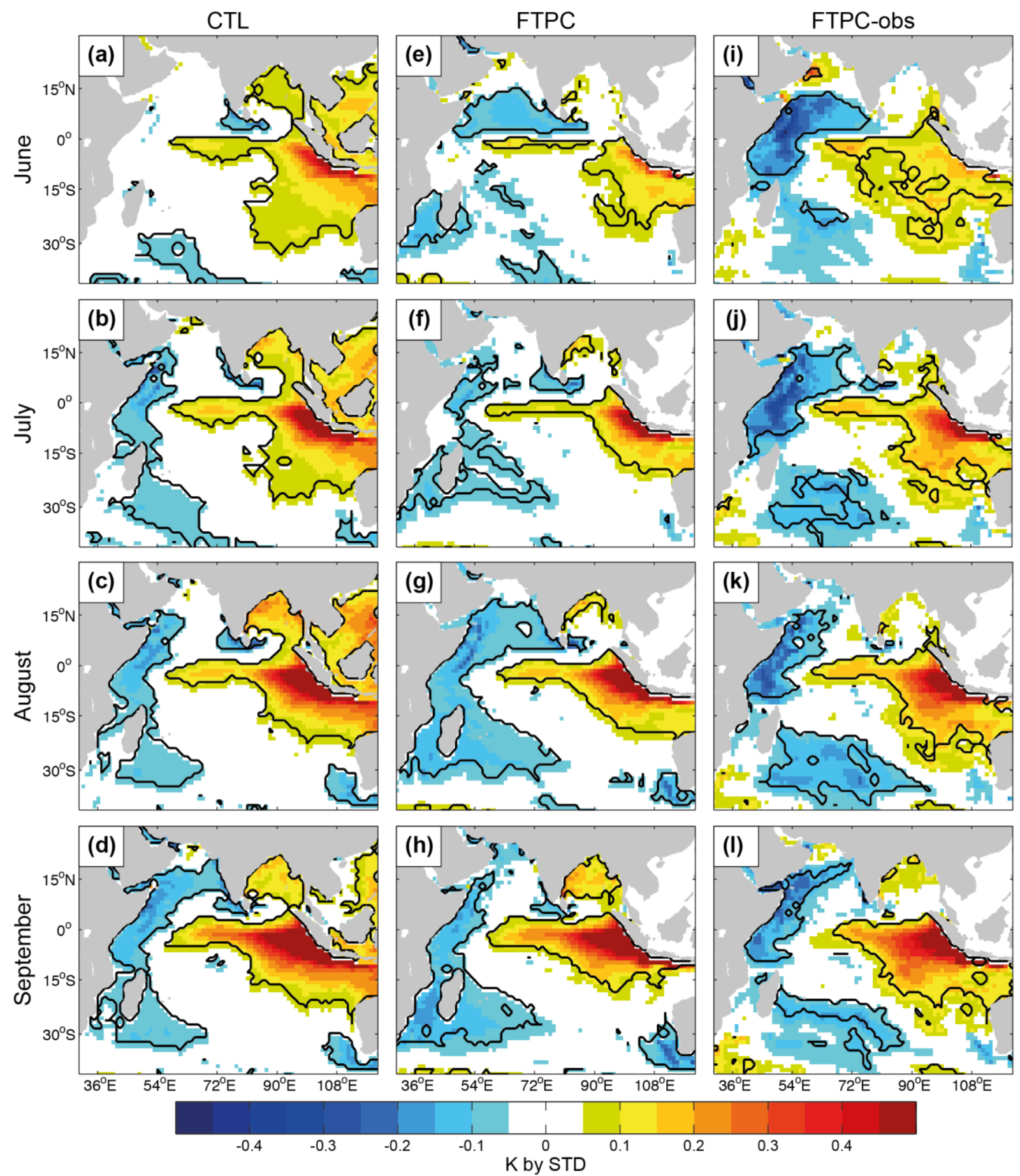

Figure 5: July to September monthly SST anomalies regressed onto normalized boreal fall (i.e., SON) eIOD SST anomalies for the (a-d) CTL, (e-h) FTPC, and (i-l) FTPC-obs experiments. Positive values correspond to warm SSTs. Black contours are anomalies significant at the $90 \%$ confidence level according to a bootstrap test. 

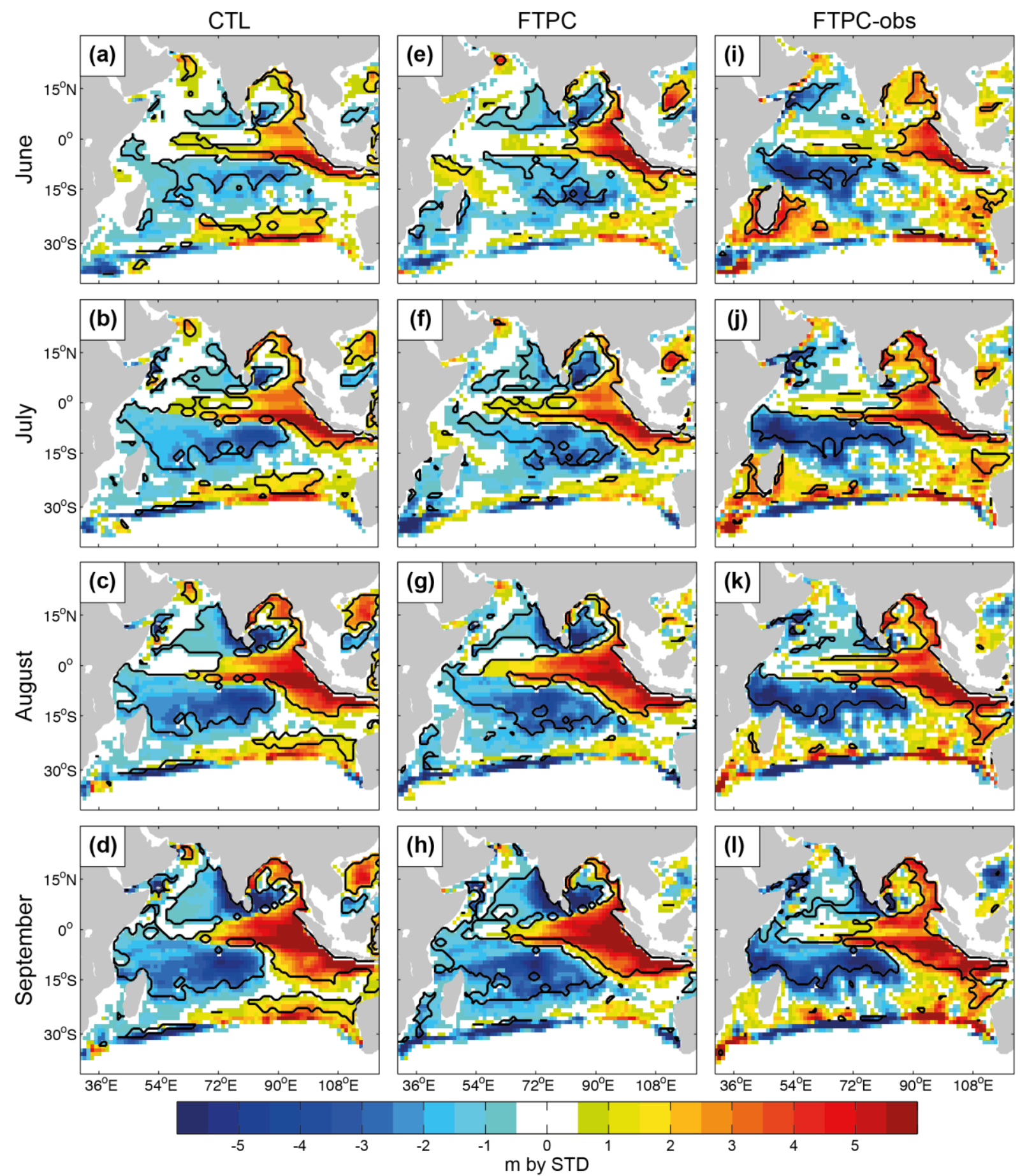

1131

1132

Figure 6: Same as Fig. 5 but for 20 d (i.e., depth of $20^{\circ} \mathrm{C}$ isotherm) anomalies. Positive values 1133 correspond to a deep thermocline. 
CTL

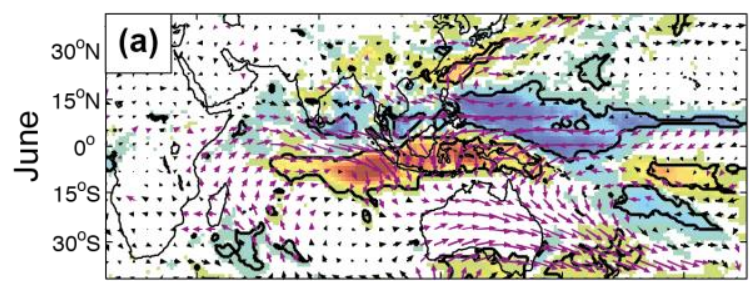

${ }_{30}^{\circ} \mathrm{N}$ (b)

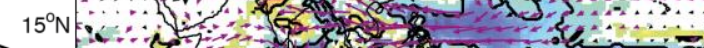

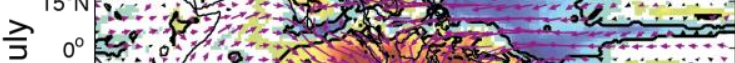

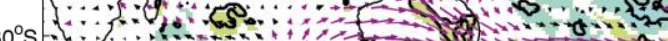

I... 1 ........

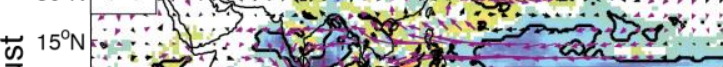

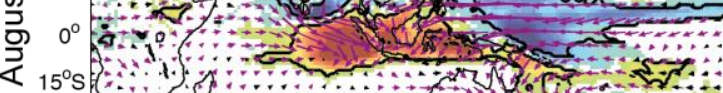

${ }^{1} \mathrm{~s}$ (

${ }^{3} \mathrm{~s}$.

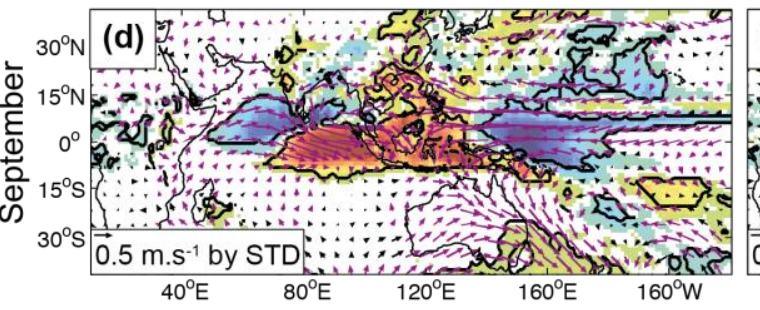

$15^{\circ} \mathrm{s}$

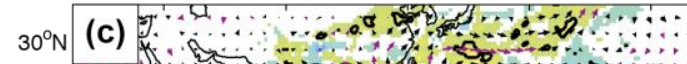

FTPC
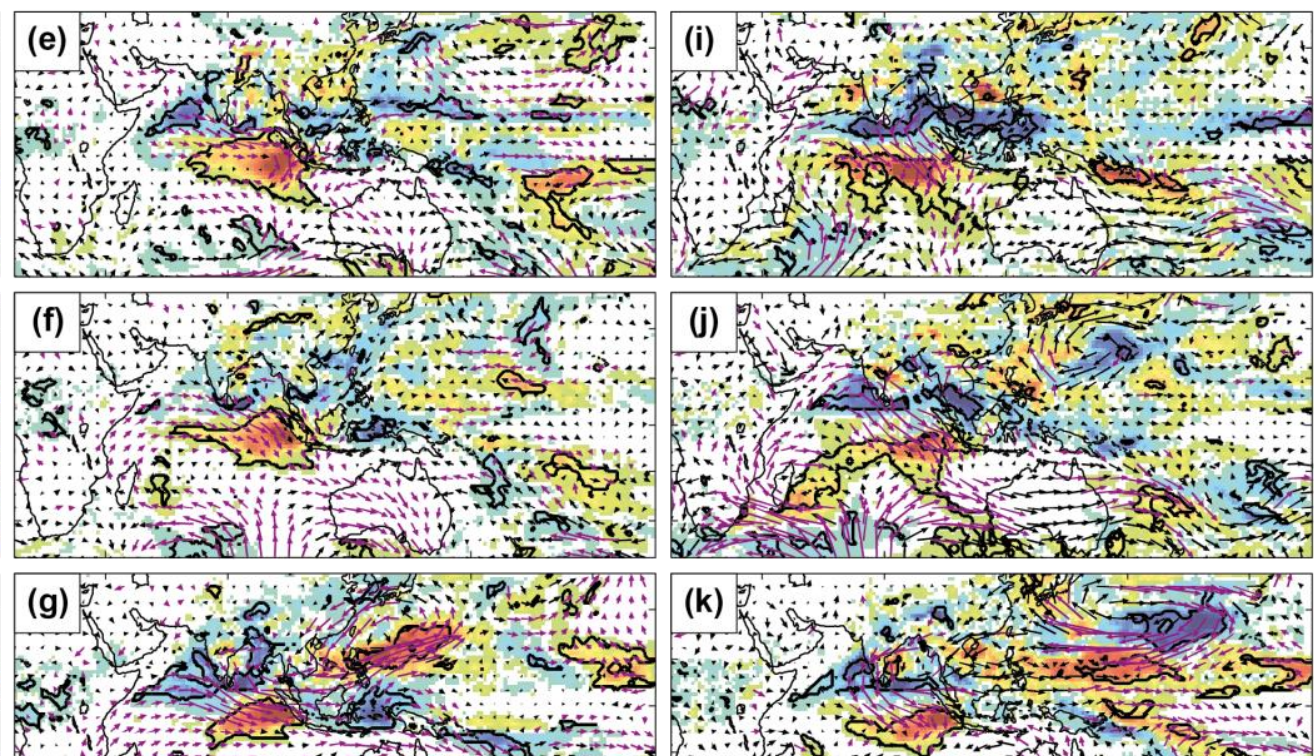

$x+5$.
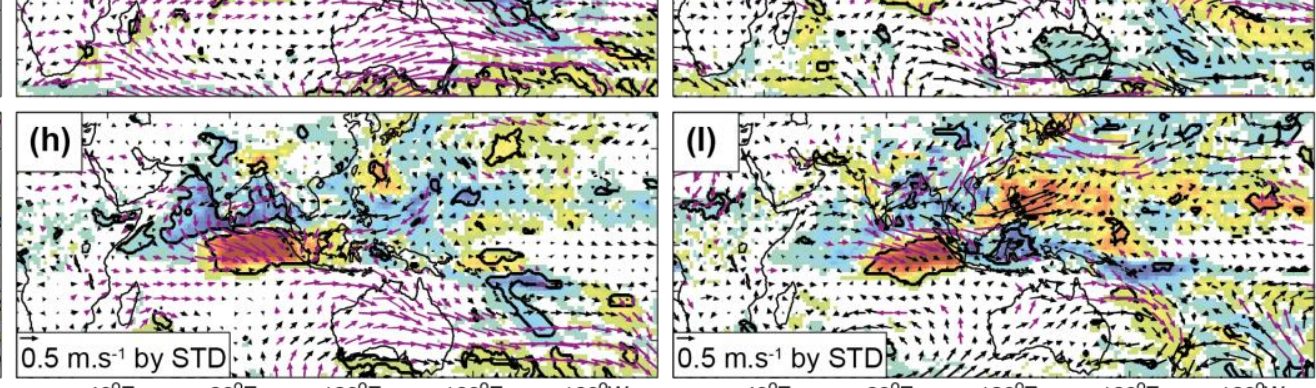

$\begin{array}{lllll}40^{\circ} \mathrm{E} & 80^{\circ} \mathrm{E} & 120^{\circ} \mathrm{E} & 160^{\circ} \mathrm{E} & 160^{\circ} \mathrm{W}\end{array}$
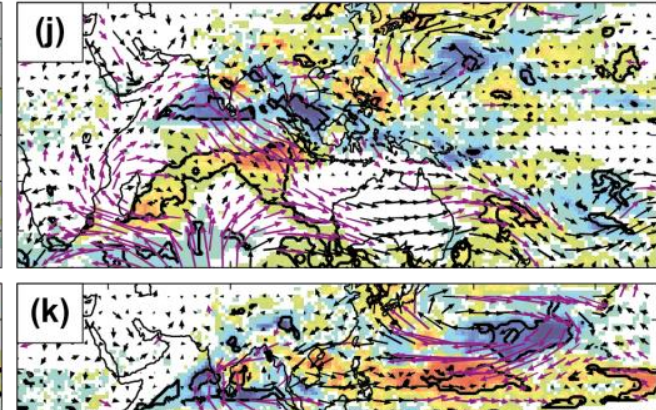

$\begin{array}{llllll}-1.6 & -1.2 & -0.8 & -0.4 & 0 & 0.4\end{array}$

Figure 7: Same as Fig. 5 but for monthly rainfall (shadings; mm.day ${ }^{-1}$ ) and 850-hPa wind (vectors; m.s ${ }^{-1}$ ) anomalies for the (a-d) CTL, (e-h) FTPC, and (i-1) FTPC-obs experiments. Black contours are significant rainfall anomalies and purple vectors are significant 850-hPa wind anomalies, both at the $90 \%$ confidence level according to a bootstrap test. 

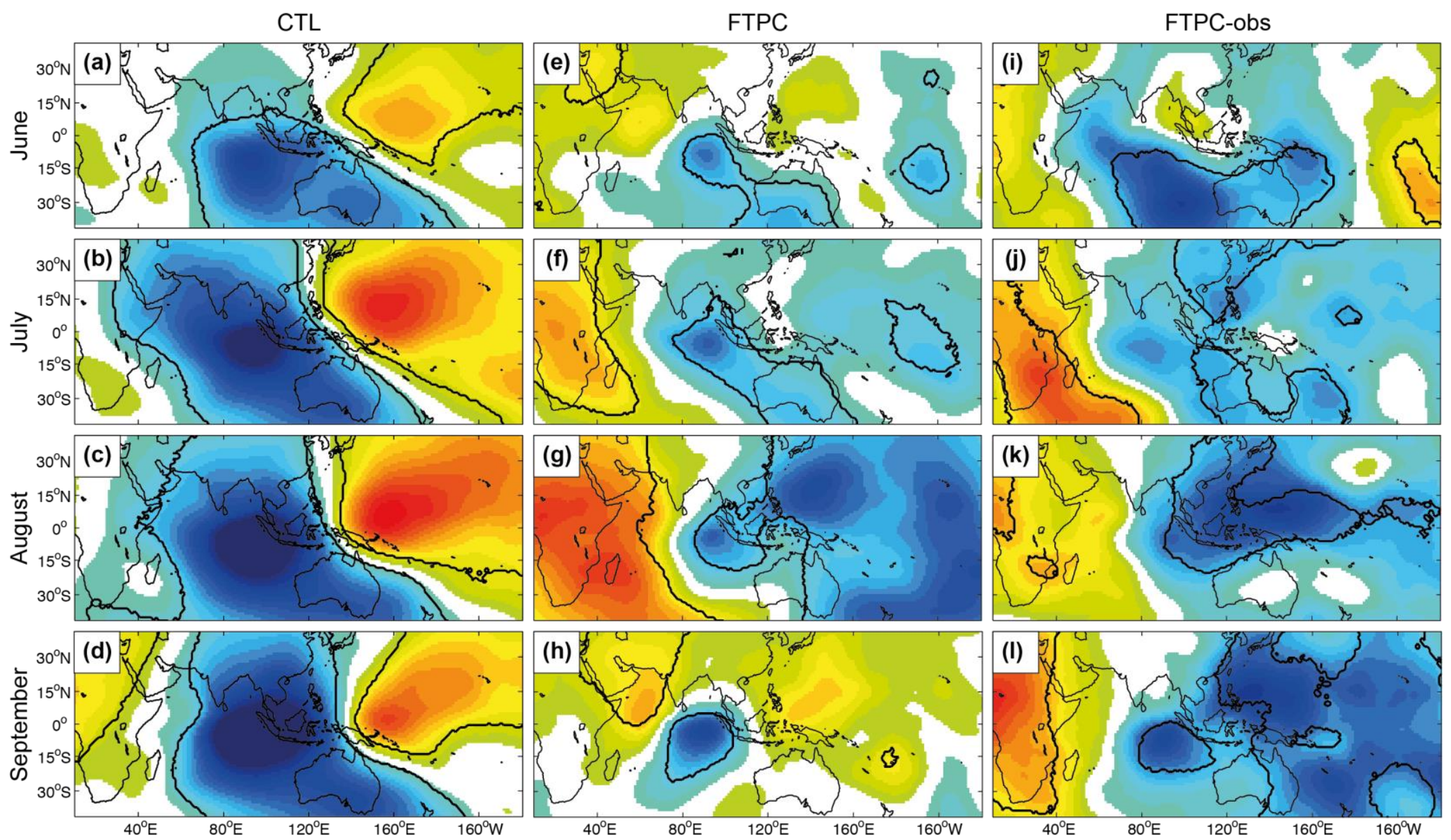

Figure 8: Same as Fig. 5 but for monthly 200-hPa velocity potential (shadings; $10^{6} \mathrm{~m}^{2} \cdot \mathrm{s}^{-1}$ ) anomalies for the (a-d) CTL, (e-h) FTPC, and (i-1) FTPC-obs experiments. Black contours are significant 200 -hPa velocity potential anomalies at the $90 \%$ confidence level according to a bootstrap 
CTL
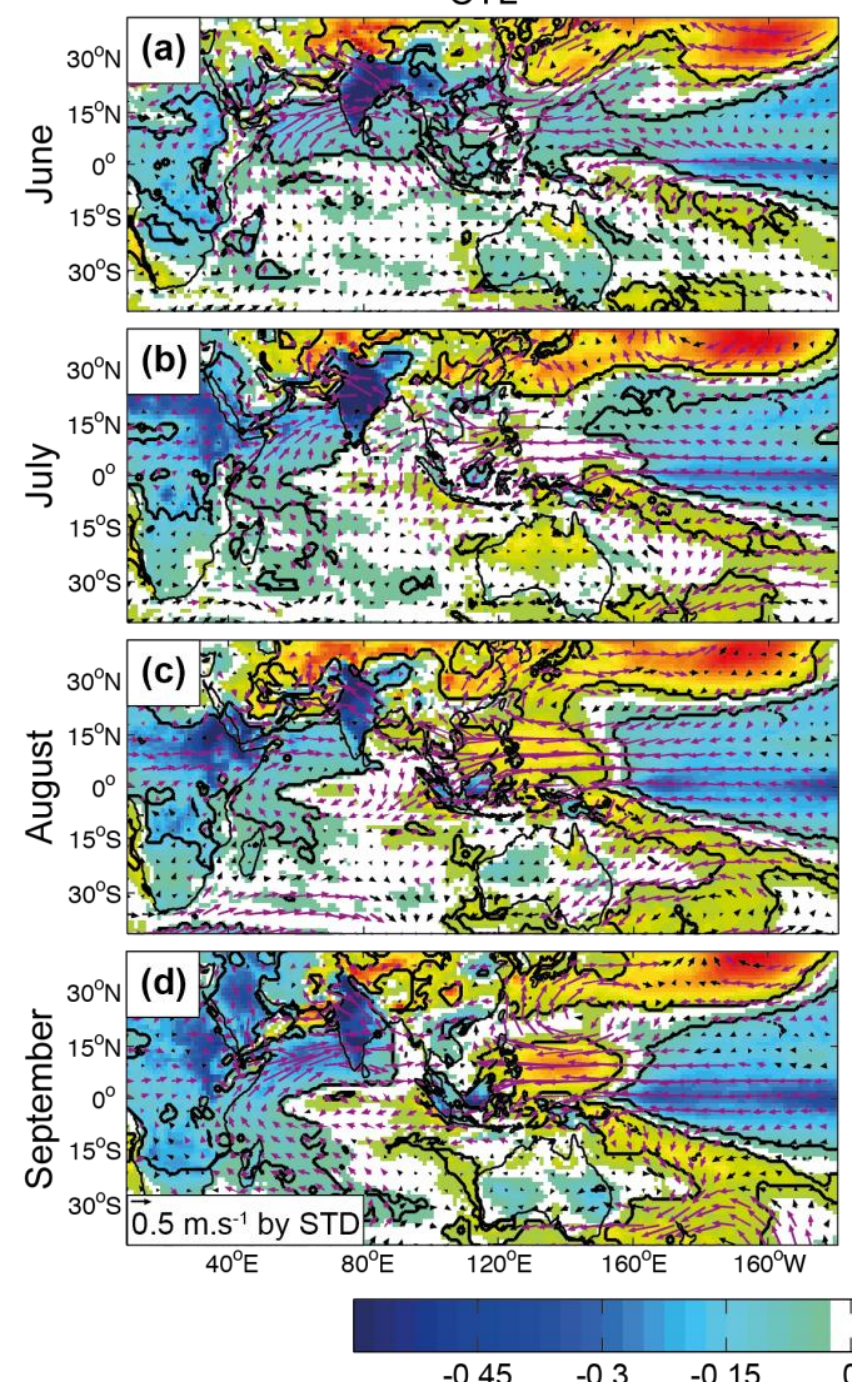

$-0.45$

1145

1146

1147

1148

1149

1150

1151
FTPC
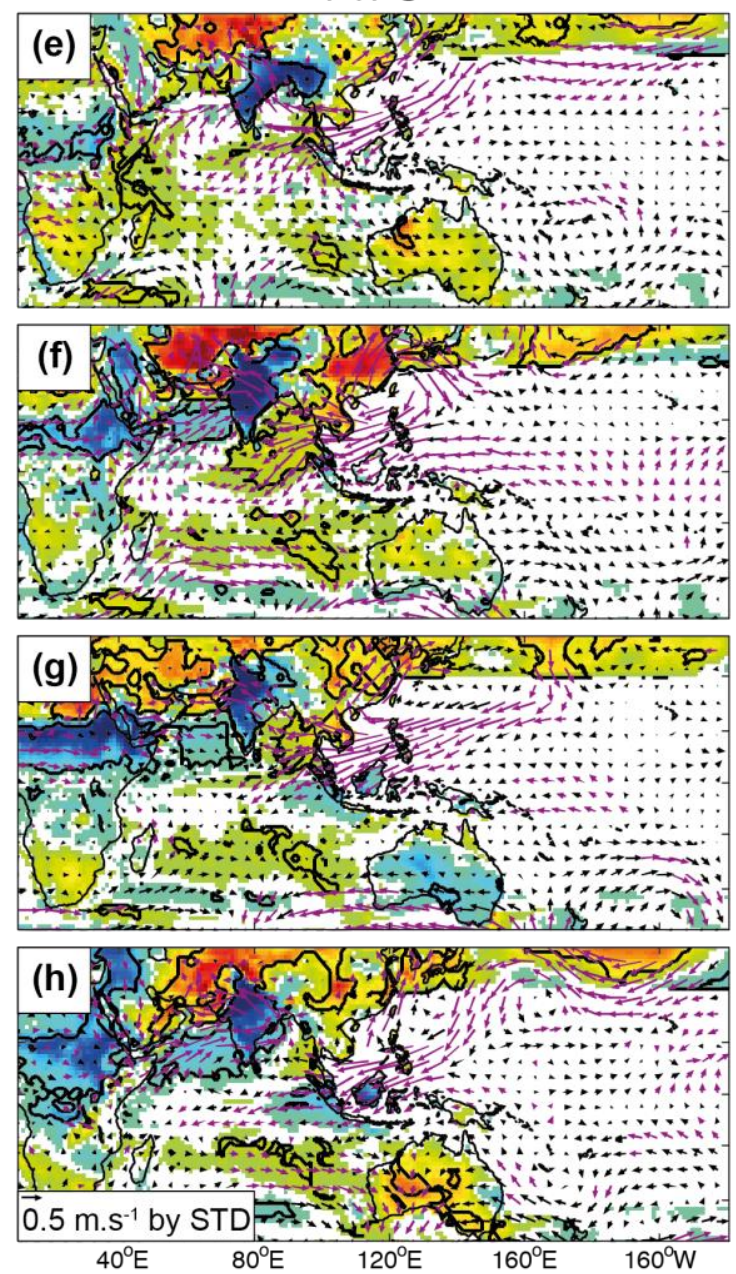

$\begin{array}{lll}0.15 & 0.3 & 0.45\end{array}$

$\mathrm{K}$ by STD

Figure 9: July to September monthly surface temperature (shadings; K) and 850-hPa wind (vectors; $\mathrm{m}^{-1} \mathrm{~s}^{-1}$ ) anomalies regressed onto normalized ISMR anomalies for the (a-d) CTL and (e-h) FTPC experiments. Black contours are significant surface temperature anomalies and purple vectors are significant $850-\mathrm{hPa}$ wind anomalies, both at the $90 \%$ confidence level according to a bootstrap test. 

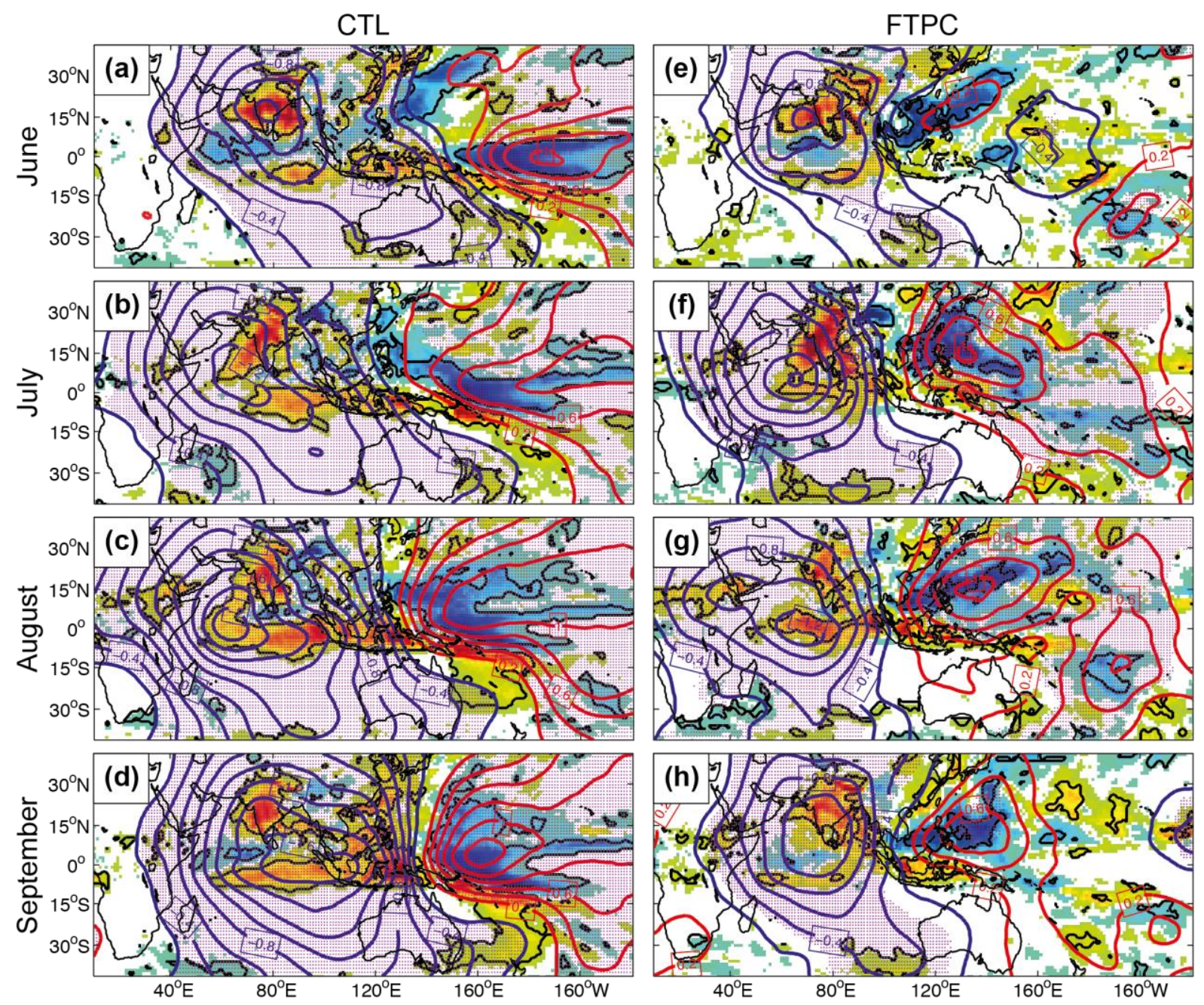

1152

1153

1154

1155

1156

1157

1158

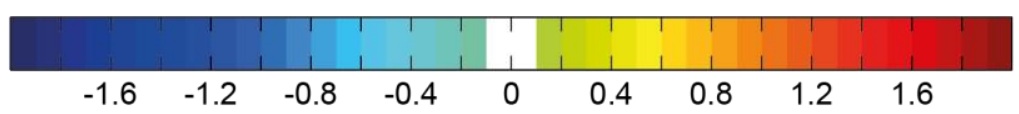

Figure 10: Same as Fig. 9 but for monthly rainfall (shadings, mm.day ${ }^{-1}$ ) and 200-hPa velocity potential (contours every $2 \times 10^{-6} \mathrm{~m}^{2} . \mathrm{s}^{-1}$ ) anomalies for the (a-d) CTL and (e-h) FTPC experiments. Black contours and purple dots are significant rainfall and $200-\mathrm{hPa}$ velocity potential anomalies at the $90 \%$ confidence level according to a bootstrap test, respectively. 